\title{
OPINIÓN
}

\section{LA REGLA DE RECIPROCIDAD PARA LA RADIODIFUSIÓN SONORA EN CHILE: UN ANÁLISIS CRÍTICO*}

\author{
Lucas Sierra \\ Universidad de Chile
}

\begin{abstract}
Resumen: Este artículo revisa críticamente la regla de reciprocidad que en 2001 la Ley de Prensa estableció para la radiodifusión sonora. El análisis muestra que la regla fue el resultado de la acción de una entidad gremial organizada,
\end{abstract}

Lucas Sierra. Abogado, Universidad de Chile. LL.M. Universidad de Yale. Ph.D. Universidad de Cambridge. Profesor de Derecho de las Telecomunicaciones, Universidad de Chile. Investigador del Centro de Estudios Públicos (CEP). Dirección electrónica: lsierra@cepchile.cl.

* Este trabajo se basa en un informe en derecho que en 2011 me encargó la Subsecretaría de Telecomunicaciones (SUBTEL), en el marco del procedimiento administrativo de fiscalización que terminó con la Resolución Exenta $N^{\circ} 6620$ de fecha 30/11/11, de esa Subsecretaría. Agradezco la ayuda de los abogados Pablo Fuenzalida Cifuentes y Carolina Tagle Alvarado en su preparación, las referencias bibliográficas que me dio José Miguel Valdivia, y las observaciones de dos árbitros anónimos durante el proceso de publicación en Estudios Públicos. Todas estas personas, sin embargo, no tienen responsabilidad alguna por los errores $\mathrm{u}$ omisiones que pueda haber. Debo señalar, además, que en 2007 hice un informe en derecho para GLR Chile Ltda. en el procedimiento de consulta ante el Tribunal de Defensa de la Libre Competencia, no contencioso $\mathrm{N}^{\mathrm{0}} 173-06$, relativo a la compra por GLR Chile Ltda. a Claxson S.A. de la totalidad de acciones de Iberoamerican Radio Chile S.A. Dicho informe está referido en la Resolución 20/2007 del TDLC (1.22.) y se encuentra agregado al respectivo expediente. 
que hace excepción a la regla general en la regulación de las telecomunicaciones, regla general que también sigue la radiodifusión televisiva. El artículo sostiene que esta es una excepción injustificada y que, por lo mismo, debería derogarse. Mientras esto no ocurra, concluye, su interpretación a la hora de aplicarse debería ser — como ha sido — restringida.

Palabras clave: radiodifusión, reciprocidad, regulación de telecomunicaciones, proceso legislativo, interpretación jurídica, Chile.

Recibido: septiembre 2012; aceptado: noviembre 2012.

\section{THE RECIPROCITY RULE ON AUDIO RADIO BROADCASTING IN CHILE: A CRITICAL ANALYSIS}

Abstract: This article critically reviews the rule on reciprocity in audio radio broadcasting that the Press Law established in 2001. The analysis shows that the rule was the outcome of action by an organized trade association and it made an exception to the general rule in telecommunications regulations. That general rule is also followed by televised broadcasting. The article holds that this is an unjustified exception and for the same reason, it must be repealed. The article concludes that until this occurs, the interpretation of the rule when it is enforced should be restricted, as it has been.

Keywords: radio broadcasting, reciprocity, telecommunications regulations, legislative process, legal interpretation, Chile.

Received: September 2012; accepted: November 2012.

"Reciprocidad: correspondencia mutua de una persona o cosa con otra" (RAE).

\section{Introducción}

\section{Q}

ste artículo estudia la regla de "reciprocidad" que la Ley de Prensa establece para la radiodifusión sonora - la "radio" — en Chile. Esta regla es un caso excepcional en la regulación de las telecomunicaciones. Ni siquiera la "otra" radiodifusión, la televisiva, contempla una 
regla así. La radiodifusión televisiva aquí es igual a la regulación general de telecomunicaciones: sin regla de reciprocidad.

La regla de reciprocidad para la radio se introdujo en 2001 y exige para la entrega de concesiones de radiodifusión sonora a personas jurídicas con participación de capital extranjero superior al 10\% que el país de origen de dicho capital disponga derechos y obligaciones similares para los chilenos.

La regla general en materia de telecomunicaciones, incluyendo hoy a la radiodifusión televisiva y, hasta 2001, a la sonora también, requiere para la entrega de concesiones que la persona jurídica respectiva esté constituida en Chile, con independencia de la nacionalidad de origen de su capital. Hay una exigencia de nacionalidad, pero ésta se aplica a la administración de la persona jurídica titular de la concesión, no a sus capitales. La regla de reciprocidad para la radio, en cambio, tiene que ver con la nacionalidad de estos capitales.

Este trabajo contiene un análisis crítico de esta regla de reciprocidad. Su carácter excepcional no parece estar en absoluto justificado, y mejor se explica por la gestión exitosa de un grupo de interés - la Asociación de Radiodifusores de Chile (ARCHI) - , durante la tramitación de la Ley de Prensa. Por lo mismo, este artículo sugiere derogar legislativamente esta regla $\mathrm{y}$, mientras esto no ocurra, interpretarla de una manera restringida a la hora de aplicarla. Así, por ejemplo, se debe considerar el control directo, y no el indirecto, en la estructura de propiedad de las personas jurídicas interesadas o titulares de las concesiones de radiodifusión sonora.

Para desarrollar este argumento, el trabajo se divide en tres partes. La primera (I) caracteriza la historia del establecimiento del inciso tercero del Art. 9 de la Ley de Prensa que la contiene. Esta historia se divide en cada uno de los trámites legislativos que siguió el proyecto que convirtió en dicha ley. Ella muestra cómo desde una comunicación al Senado de la ARCHI a principios de 1996, el rumbo del proceso legislativo cambia y se consagra la regla sólo para la radio. La segunda (II), a partir de un análisis crítico su historia legislativa, propone y justifica un sentido restringido para ella. La última parte (III) concluye. 


\section{Historia ${ }^{1}$}

¿Cómo está formulada, textualmente, la regla? Así, en el inciso tercero del Art. $9^{\circ}$ de la Ley 19.733, Ley de Prensa, de 2001:

Las concesiones para radiodifusión sonora de libre recepción solicitadas por personas jurídicas con participación de capital extranjero superior al diez por ciento, sólo podrán otorgarse si se acredita, previamente, que en su país de origen se otorga a los chilenos derechos y obligaciones similares a las condiciones de que gozarán estos solicitantes en Chile. Igual exigencia deberá cumplirse para adquirir una concesión ya existente. La infracción al cumplimiento de esta condición significará la caducidad de pleno derecho de la concesión ${ }^{2}$.

${ }^{1}$ Las referencias a la historia del establecimiento de la Ley de Prensa se harán a las actas oficiales de dicho procedimiento legislativo, así: $\mathrm{CD}=$ Cámara de Diputados, $\mathrm{S}=$ Senado, número de la sesión, día/mes/año. Dichas actas están disponibles en: http://www.leychile.cl/Consulta/portada_hl?tipo_ norma $=$ XX1\&nro_ley $=19733 \&$ anio $=2012$

${ }^{2}$ Los primeros dos incisos del Art. $9^{\circ}$ disponen: "En los casos en que la ley permita que el propietario de un medio de comunicación social sea una persona natural, ésta deberá tener domicilio en el país y no haber sido condenada por delito que merezca pena aflictiva. Tratándose de personas jurídicas, éstas deberán tener domicilio en Chile y estar constituidas en el país o tener agencia autorizada para operar en territorio nacional. Su presidente y sus administradores o representantes legales deberán ser chilenos y no haber sido condenados por delito que merezca pena aflictiva. La condena a la pena señalada hará cesar al afectado, de inmediato, en toda función o actividad relativa a la dirección, administración o representación en el medio de comunicación social en que la desempeñe.

“Todo medio de comunicación social deberá proporcionar información fidedigna acerca de sus propietarios, controladores directos o indirectos, arrendatarios, comodatarios o concesionarios, según fuere el caso. Si ellos fueren una o más personas, dicha información comprenderá la que sea conducente a la individualización de las personas naturales y jurídicas que tengan participación en la propiedad o tengan su uso, a cualquier título. Asimismo, comprenderá las copias de los documentos que acrediten la constitución y estatutos de las personas jurídicas que sean socias o accionistas, salvo en los casos de sociedades anónimas abiertas, así como las modificaciones de los mismos, según correspondiere. La referida información será de libre acceso al público y deberá encontrarse permanentemente actualizada y a su disposición en el domicilio del respectivo medio de comunicación social y de las autoridades que la requieran en el ejercicio de sus competencias. Si ellos fueren una o más personas, dicha información comprenderá la que sea conducente a la individualización de las personas naturales 
En lo que inmediatamente sigue, la historia de su establecimiento legislativo.

\subsection{Mensaje}

Ley de Prensa dictada en 2001 remplazó a la Ley 16.643 de 1967 sobre Abusos de Publicidad. Ella se inició por un Mensaje enviado al Congreso en 1993. Ese texto original no contemplaba ninguna regla de reciprocidad. Ésta fue incorporada luego en el Congreso.

En materia de propiedad de los medios de comunicación — lugar de la ley en que la regla de reciprocidad fue luego insertada-, el proyecto original básicamente repetía lo dispuesto en la Ley 16.643 que estaba reformando. La propiedad de los medios era regulada por esta ley en función de ayudar a que la responsabilidad por las infracciones a ella pudiera hacerse efectiva.

En este sentido, la ley se preocupaba de individualizar y radicar a los propietarios de los medios de comunicación, imponiendo condiciones de nacionalidad, domicilio y residencia. Así lo disponía el texto original del proyecto de ley enviado al Congreso en 1993, en su Art. 12, que reproducía los dos primeros incisos del Art. 5 de la Ley $16.643^{3}$ :

El propietario de todo diario, revista o escrito periódico cuya
dirección editorial se encuentre en Chile; el de toda agencia
noticiosa nacional, y el propietario o concesionario de toda

y jurídicas que tengan participación en la propiedad o tengan su uso, a cualquier título. Asimismo, comprenderá las copias de los documentos que acrediten la constitución y estatutos de las personas jurídicas que sean socias o accionistas, salvo en los casos de sociedades anónimas abiertas, así como las modificaciones de los mismos, según correspondiere. La referida información será de libre acceso al público y deberá encontrarse permanentemente actualizada y a su disposición en el domicilio del respectivo medio de comunicación social y de las autoridades que la requieran en el ejercicio de sus competencias".

${ }^{3}$ Decía el primer inciso: "El propietario de todo diario, revista o escrito periódico cuya dirección editorial se encuentre en Chile, o agencia noticiosa nacional, y el concesionario de toda radiodifusora o estación de televisión, deberán ser chilenos y tener domicilio y residencia en el país”. Y seguía el segundo: "Si dicho propietario o concesionario fuere una sociedad o comunidad se considerará chilena siempre que pertenezca a personas naturales o jurídicas chilenas el $85 \%$ del capital social o de los derechos de la comunidad. Las personas jurídicas que sean socios o formen parte de la comunidad o sociedad propietaria deberán tener, también, el $85 \%$ de su capital en poder de chilenos”. 
emisora de radiodifusión sonora o televisual deberán ser chilenos y tener domicilio y residencia en el país. Si dicho propietario o concesionario fuese una sociedad o comunidad se considerará chilena siempre que pertenezca a personas naturales o jurídicas chilenas el ochenta y cinco por ciento (85\%) del capital social o de los derechos de la comunidad. Las personas jurídicas que sean socios o formen parte de la comunidad o sociedad propietaria deberán tener, también, el ochenta y cinco por ciento ( $85 \%$ ) de su capital en poder de chilenos ${ }^{4}$.

\subsection{Cámara de Diputados, primer trámite constitucional}

Así, entonces, la actual Ley de Prensa fue enviada a la Cámara de Diputados sin regla de reciprocidad. El proyecto de ley comenzó a ser estudiado por la Comisión de Constitución, Legislación y Justicia, la que emitió su primer informe dos años después. En lo que aquí interesa, la Comisión básicamente aprobó el Art. 12 original, pasando a ser Art. 10, y le agregó un par de puntos en el inciso primero y, además, un segundo inciso. Así quedó:

El propietario de un medio de comunicación social y el titular de una concesión o permiso de un servicio de radiodifusión sonora, cuando se trate de una persona natural, deberá ser chileno, tener domicilio en el país y no estar procesado ni haber sido condenado por delito que merezca pena aflictiva. Tratándose de personas jurídicas de derecho público o privado, deberán estar constituidas en Chile y tener domicilio en el país. Su presidente, gerente, administradores y representantes legales deberán ser chilenos y no estar procesados ni haber sido condenados por delito que merezca pena aflictiva.

En el domicilio de los medios de comunicación social deberá existir, a disposición de cualquier persona que lo solicite, el nombre e individualización completa de la o las personas naturales o jurídicas propietarias del medio de que se trata, con indicación precisa del porcentaje, monto y modalidades de su participación en la propiedad o en el capital de la empresa, todo esto debidamente actualizado (CD: 02, 16/05/95, p. 84).

${ }^{4}$ CD (Cámara de Diputados): 15, 08/07/93, p. 17. 
¿Qué fue lo agregado? En el inciso primero, se dispuso que en el caso de propietarios de medios de comunicación social y titulares de concesiones de radiodifusión sonora que sean personas naturales, éstas no deberían haber sido condenadas por delitos con pena aflictiva. Así, a los requisitos de nacionalidad y domicilio, se agregó un requisito de, digamos, "idoneidad moral": el no haber sido condenado por tales delitos. Y también se agregó respecto a la administración de las personas jurídicas propietarias la exigencia de que los gerentes, administradores y representantes legales de las personas jurídicas propietarias sean chilenos y no hayan sido procesados ni condenados por esos delitos.

A su vez, se agregó un inciso segundo que añade un requisito de publicidad con el objeto de afianzar todavía más el principio de responsabilidad que se perseguía con este artículo: se exige a los medios de comunicación poner a disposición del público la identificación y características de su propiedad, como un medio de verificar el cumplimiento de lo que la ley dispone respecto de ella.

En el debate legislativo, este requisito de publicidad fue entendido como un paso hacia la "transparencia" del sistema de medios de comunicación. Así, por ejemplo, lo señaló el diputado Zarko Luksic:

...También se establece una norma de transparencia. Uno de los grandes problemas del ámbito de los medios de comunicaciones es el desconocimiento que hay sobre la titularidad de quienes ostentan su capital. Para dar una mayor transparencia, se establece que cualquier persona puede informarse sobre la participación en el capital de la empresa. Esto posibilita disponer de una información fidedigna de los distintos aportes de capital, tanto nacionales como extranjeros, en las empresas periodísticas (CD: 06, 07/06/95, p. 104).

Algo similar apuntó el diputado José Antonio Viera-Gallo: "Se logró mayor transparencia sobre la propiedad de los medios. Es necesario que sepamos, de una vez por todas, a quién pertenece un medio y que no sea un misterio saber quién está detrás de una revista, de un diario, de una radio, etcétera" (CD: 06, 07/06/95, 112).

Como colegislador, el gobierno de la época también vio en el nuevo inciso segundo un paso hacia la transparencia, es decir, un paso hacia la posibilidad de saber, con facilidad, quién es efectivamente dueño de un medio de comunicación. José Joaquín Brunner, el Ministro Secretario General de Gobierno, dijo a la Cámara de Diputados: 
En cuanto a la estructura y organización de la industria de medios en Chile, debo señalar que los indicadores disponibles sobre su participación de mercado no se apartan en general de aquellos observados en los demás países democráticos a nivel internacional. Como en ellos, hay aquí grupos de propiedad cruzada, fenómenos de integración horizontal y multimedia y presencia de capitales extranjeros [...] El proyecto en discusión se hace cargo de estos fenómenos al proteger el pluralismo y la diversidad de medios por la vía de la transparencia y la competencia, buscando evitar así la constitución de monopolios y la formación de concentraciones excesivas, más que por una detallada reglamentación que fije cuotas de mercado o introduzca otros arbitrios de control administrativo que, en la práctica, podrían limitar o distorsionar los derechos que deseamos cautelar y promover (CD: 06, 07/06/95, pp. 109-110).

De esta forma, entonces, el Art. 10 fue aprobado en primer trámite constitucional. Es interesante apuntar que generó amplio consenso, registrándose una sola indicación al proyecto, de la diputada Fanny Pollarolo. Ella propuso que para el caso de "personas jurídicas con fines de lucro" propietarias de un medio de comunicación social "la mayoría de los socios deberán ser de nacionalidad chilena y en ningún caso más del 30\% del capital social podrá pertenecer directa o indirectamente a personas de nacionalidad extranjera" (CD: 28, 09/08/95, p. 145). La indicación pretendía reducir la participación de propiedad extranjera sobre los medios de comunicación organizados como personas jurídicas: de $85 \%$, como era la propuesta original que, a su vez, estaba en línea con la historia, a 30\%. La indicación fue rechazada.

Así aprobado el proyecto de ley, con el Art. 10 citado y sin regla de reciprocidad, fue enviado el 12/09/95 al Senado.

\subsection{Senado, segundo trámite constitucional}

Fue al inicio de este segundo trámite constitucional que dicha regla comenzó a fraguarse al interior de la Comisión de Constitución, Legislación, Justicia y Reglamento del Senado. Sus miembros discutieron sobre la conveniencia de continuar imponiendo requisitos de nacionalidad a los propietarios de medios de comunicación. Como se dijo más arriba, la exigencia de ser chileno - ya sea como persona natural o 
jurídica - venía de la legislación vigente a la época de este proyecto de ley, exigencia que éste reprodujo y la Cámara de Diputados aprobó sin problemas. Pero los senadores de la Comisión pensaron distinto.

El primer informe de la Comisión consigna que entre ellos la exigencia de nacionalidad despertó críticas. Aludieron al creciente proceso de internacionalización que estarían experimentando los medios de comunicación, proceso en el que dicha exigencia estaría deviniendo obsoleta. Dice el primer informe:

Se estimó que los requisitos de nacionalidad correspondían a épocas pasadas, y hoy en día, en un contexto de internacionalización creciente de los medios de comunicación social, han perdido sustento y pudieran resultar limitativos para el ejercicio de la libertad de informar. Además, podrían incluso resultar negativos para los chilenos que quisieran desempeñarse en los medios de comunicación de otros países, consideraciones que aconsejaron suprimir estos requisitos para los dueños de medios de comunicación social, de modo de contemplar sólo exigencias de índole general. (S: 42, 09/04/97, p. 388).

Los miembros de la Comisión estaban conscientes de la importancia que tenía el objetivo al cual la exigencia de nacionalidad estaba unida: garantizar la posibilidad de hacer efectiva la responsabilidad de quienes incurrieran en las infracciones establecidas por la ley. Pero estimaron mejor asegurarla mediante la exigencia de contar con domicilio en el país y una exigencia de nacionalidad para la plana administrativa, pero no mediante la nacionalidad de los propietarios. Con tal que se constituyeran y tuvieran domicilio en Chile, los dueños podían ser extranjeros. Sólo debían ser chilenos quienes tuvieran facultades de administración y representación legal. Sigue su primer informe:

Estas consideraciones aconsejarían suprimir las normas que establecen requisitos de nacionalidad para los dueños de medios de comunicación social, de modo de contemplar sólo exigencias de índole general. En ese sentido, se estimó adecuado pedir domicilio en el país en caso de que el propietario del medio de difusión sea una persona natural, además de los requisitos de idoneidad moral suficientes, reflejados en el hecho de que no esté procesado ni hubiera sido condenado a pena aflictiva. 
Tratándose de una persona jurídica, se creyó necesario exigir que esté constituida en Chile y tenga domicilio en el país. El requisito de la nacionalidad operará, no para ella, sino para quienes actúen en calidad de presidente, administradores o representantes legales de la misma (S: 42, 09/04/97, p. 389).

De esta manera, se diferenciaría entre la propiedad y la administración del medio de comunicación social, en el sentido de que es esta última la que debe estar en manos de chilenos, en lo que respecta al presidente o administrador y al representante legal.

Con este giro, los integrantes de la Comisión ponían al proyecto de ley de prensa en línea con lo que las leyes de telecomunicaciones y televisión ya disponían sobre estas materias.

La Ley 18.168, General de Telecomunicaciones, no exige nacionalidad a los propietarios de concesiones o permisos de telecomunicaciones. En el caso de las concesiones, por ejemplo, el inciso primero del Art. 21 dispone:

Sólo podrán ser titulares de concesión o hacer uso de ella, a cualquier título, personas jurídicas de derecho público o privado, constituidas en Chile y con domicilio en el país. Sus Presidentes, Directores, Gerentes, Administradores y representantes legales no deberán haber sido condenados por delito que merezca pena aflictiva.

$\mathrm{Y}$ el inciso primero de su Art. $22^{\circ}$ precisa:

Los Presidentes, Gerentes, Administradores y representantes legales de una concesionaria de radiodifusión de libre recepción, además de los requisitos establecidos en el artículo precedente, deberán ser chilenos. Tratándose de Directorios, podrán integrarlo extranjeros, siempre que no constituyan mayoría.

La legislación de telecomunicaciones, entonces, no exige nacionalidad a los propietarios de las autorizaciones para prestar los servicios que regula. Sólo exige que se constituyan en Chile, que se domicilien en el país, y que la administración y representación legal sea chilena. Además, estas últimas no deben haber sido condenadas por delitos que merezcan pena aflictiva. Es interesante, en fin, lo que dispone para 
las concesionarias de radiodifusión de libre recepción: sus directorios pueden ser integrados por extranjeros, en la medida en que no sean mayoría. Esta regla especial no hace excepción a la regla general en el sentido de no exigir nacionalidad a la propiedad, pues sólo exige nacionalidad, bajo ciertas condiciones, a los representantes de esta propiedad en el mencionado órgano de gobierno corporativo. No la exige a la propiedad misma.

Por su parte, la Ley 18.838 crea el Consejo Nacional de Televisión, dispone en el primer inciso de su Art. $18^{\circ}$ :

Sólo podrán ser titulares de una concesión de servicio de radiodifusión televisiva de libre recepción o hacer uso de ella, a cualquier título, personas jurídicas de derecho público o privado, constituidas en Chile y con domicilio en el país. Sus presidentes, directores, gerentes, administradores y representantes legales deberán ser chilenos y no haber sido condenados por delito que merezca pena aflictiva.

De nuevo, la ley de televisión sigue la línea de la ley de telecomunicaciones: no exige nacionalidad a los propietarios, sólo que la respectiva persona jurídica se constituya en Chile y se domicilie aquí. La nacionalidad es un requisito sólo para los administradores y representantes legales, quienes, además, no deben haber sido condenados por delitos que merezcan pena aflictiva.

En esto estaba la Comisión de Constitución, Legislación, Justicia y Reglamento del Senado, considerando poner en línea la futura legislación de prensa con las leyes mencionadas, cuando entró en escena la Asociación de Radiodifusores de Chile (ARCHI). Y el curso de los acontecimientos cambió.

El 28/02/96, la ARCHI dirigió al presidente de la Comisión un documento con "observaciones" al proyecto de ley. En el punto que aquí interesa, señaló:

Estimamos que en materia de radiodifusión las normas sobre propiedad e inversión extranjera obedecen a distintos padrones de los que rigen en prensa y televisión. La radio es un medio fundamentalmente estratégico y de gran penetración cultural en la comunidad y además es necesario resguardar su pluralismo y una leal competencia dentro del proceso de globalización e internacionalización de nuestra economía. De aquí que 
estimemos fundamental que, manteniendo el principio de una libertad de mercado, se exija total reciprocidad de derechos y obligaciones respecto a lo existente en el país de origen de las eventuales inversiones extranjeras. Correspondería al Ministerio de Transportes y Telecomunicaciones, a través de su Subsecretaría de Telecomunicaciones, establecer y autorizar en cada caso estas inversiones teniendo en consideración el respeto de estos principios. Solicitamos que estas normas sean incorporadas en el art. 10 del proyecto en estudio.

En este documento de la ARCHI, entonces, está el origen de la regla de reciprocidad. Los senadores de la Comisión no habían concebido algo así, porque, como vimos, habían desvinculado la nacionalidad de la propiedad de los medios ${ }^{5}$.

Un tiempo después, el 22/08/96, la ARCHI envió un nuevo documento, esta vez con propuestas más elaboradas sobre la reciprocidad. Para la ARCHI ellas eran "altamente necesarias para el interés nacional y el desenvolvimiento de la radiodifusión". Al respecto, señaló:

[La propuesta] dice relación con el proceso de integración de Chile al Mercosur y la participación de los radiodifusores en él. Somos fervientes partidarios de la libertad de información y de avanzar en este proceso continental, en condiciones de equidad para las diferentes actividades de los países comprometidos, por lo que estimamos que debe haber similaridad en el tratamiento mutuo para éstas. La indicación que podría incluirse como inciso tercero del artículo $9^{\circ}$ del proyecto, que trata de los propietarios de los medios, es la siguiente:

En el caso de concesiones para radiodifusión de libre recepción solicitadas por personas jurídicas extranjeras o chilenas, con participación de capital extranjero, el ministerio de transportes y telecomunicaciones, sólo podrá otorgarla si se acredita, previamente, que en el país de origen se otorgan a los chilenos derechos y obligaciones recíprocas y similares a las condiciones de que gozarán estos solicitantes en Chile. Igual exigencia deberá cumplirse para adquirir una concesión existente. La infracción al cumplimiento de esta condición significará la caducidad de pleno derecho de la concesión (S: $42,09 / 04 / 97,390)^{6}$.

\footnotetext{
5 Véase esta carta en Anexo 1.

${ }^{6}$ Véase esta carta en el Anexo 2, abajo, p. 41.
} 
Y un par de semanas después, el 05/09/96, la ARCHI volvió a la carga con un tercer documento, esta vez firmado, además, por la Asociación Nacional de la Prensa (ANP), la Asociación Nacional de Televisión (ANATEL) y la Federación de Medios de Comunicación Social ${ }^{7}$. En él se dice, a favor de la regla de reciprocidad:

En el proceso de libertad de comercio e intercambio que Chile está impulsando, con el Mercosur especialmente, es preciso que nuestro país se integre en condiciones de igualdad y equidad con sus vecinos. La radio, por su influencia en la opinión pública y su carácter estratégico en lo geopolítico, requiere de un status de reciprocidad frente a sus socios en la integración. No es justo ni conveniente que, mientras los radiodifusores de otros países pueden establecerse libremente en Chile, los chilenos no puedan instalar emisoras en dichos países. El art. $9^{\circ}$ del proyecto de ley, al abolir toda mención a la nacionalidad en la propiedad de los medios, como lo hacía la Ley 16.643 sobre Abusos de Publicidad, dejó a la radiotelefonía chilena en inferioridad de condiciones frente a la de otros países. De aquí la necesidad de esta mención especial.

Los esfuerzos de la ARCHI, cuyos representantes fueron además recibidos por la Comisión (S: 42, 09/04/97, 355), tuvieron resultados. Los senadores Sergio Fernández, Juan Hamilton, Hernán Larraín, Miguel Otero y Anselmo Sule, miembros de la Comisión, decidieron incorporar una regla de reciprocidad en materia de radiodifusión en el sentido propuesto por ese ente gremial. Ésta fue la regla que aprobaron, como inciso tercero del Art. 9 que la Comisión incluyó en su primer informe ${ }^{8}$ :

${ }^{7}$ Véase esta carta en el Anexo 3, abajo, p. 45.

${ }^{8}$ Los primeros dos incisos del Art. 9 aprobados por la Comisión en su primer informe fueron: En los casos en que la ley permita que el propietario de un medio de comunicación social sea persona natural, ésta deberá tener domicilio en el país y no estar procesada ni haber sido condenada por delito que merezca pena aflictiva. Tratándose de personas jurídicas, éstas deberán estar constituidas en Chile y tener domicilio en el país. Su presidente, administradores o representantes legales deberán ser chilenos y no estar procesados ni haber sido condenados por delito que merezca pena aflictiva. En ambos casos, el auto de procesamiento por delito que merezca pena aflictiva suspenderá al afectado, de inmediato y por el tiempo que se mantenga, de cualquier función o actividad relativa a la administración del medio y de toda función periodística. 
Las concesiones para radiodifusión de libre recepción solicitadas por personas jurídicas extranjeras o chilenas, con participación de capital extranjero superior al 10\%, sólo podrán otorgarse si se acredita, previamente, que en el país de origen se otorgan a los chilenos derechos y obligaciones similares a las condiciones de que gozarán estos solicitantes en Chile. Igual exigencia deberá cumplirse para adquirir una concesión existente. La infracción al cumplimiento de esta condición significará la caducidad de pleno derecho de la concesión (S: 42, 09/04/96, 494-495).

Como se ve, la regla de reciprocidad del inciso tercero del Art. 9 recién transcrita, es muy parecida a la vigente hoy. Tiene, sin embargo, una diferencia significativa: no es, como hoy, sólo una regla para la radio (o radiodifusión "sonora", como se le conoce técnicamente), sino para la radiodifusión en general. Es decir, para la radiodifusión "sonora" (radio) y para la radiodifusión "televisiva" (TV).

La historia fidedigna de la Ley 19.733 no registra razones ni debate en la Comisión para incorporar esta regla de reciprocidad al proyecto de ley que, como se ha dicho, no la contemplaba originalmente. $\mathrm{Y}$ habría sido esperable algún debate y justificación, ya que se estaba introduciendo una innovación que se separaba de lo que en este punto disponían las leyes de telecomunicaciones y de televisión, que no exigían nacionalidad a la propiedad de las concesiones: la regla de reciprocidad es una exigencia de nacionalidad. Cabe recordar que esta regla se refería a la radiodifusión en general, sin distinguir entre sonora y televisiva. Esto significa que en este punto se estaban reformando las leyes de telecomunicaciones y de televisión.

Así, sin mayor discusión sobre esta importante reforma, se fue el proyecto a la sala del Senado para su discusión en general.

\subsubsection{Sala del Senado, discusión en general}

En la Sala, el senador Sergio Fernández explicó a sus colegas que la regla de reciprocidad para la radiodifusión se había incorporado

La individualización del propietario o titular de la concesión o permiso, según el caso, deberá mantenerse estrictamente al día, como también, tratándose de personas jurídicas, los nombres de sus socios y el registro de accionistas, según corresponda. Esta información será pública y deberá estar permanentemente a disposición de cualquier persona en el domicilio social. 
"recogiendo indicaciones de los medios de comunicación, y fundamentalmente de la ARCHI (Asociación de Radiodifusores de Chile)". Agregó que ésta "es una aspiración muy sentida de los radiodifusores nacionales, y nos parece perfectamente lógica. Chile está en situación de permitir a los extranjeros operar también en el campo de las concesiones para radiodifusión de libre recepción; pero, naturalmente, a nuestros conciudadanos se les debe otorgar igual derecho en el respectivo país de origen" (S: 45, 06/05/97).

Se abrió plazo para indicaciones y el proyecto volvió luego a la Comisión para su segundo informe.

\subsubsection{Comisión de Constitución, Justicia y Reglamento, segundo informe}

En la Comisión ocurre algo muy interesante: se precisa que la regla de reciprocidad se refiere a la radiodifusión "sonora" y no a la televisiva. Con esto no se reformó la ley de televisión en este punto, sólo la de telecomunicaciones. Tampoco se registraron razones para aplicar la regla a la radiodifusión sonora y no a la televisiva (S: 02, 01/10/97, 635). Es de lamentar, puesto que preguntar por qué es ineludible al considerar que ambas radiodifunden como medios de comunicación usando el espectro radioeléctrico.

La regla de reciprocidad del inciso tercero del Art. 9, aprobado por la Comisión en su segundo informe, es la vigente hasta hoy:

Las concesiones para radiodifusión sonora de libre recepción solicitadas por personas jurídicas con participación de capital extranjero superior al $10 \%$, sólo podrán otorgarse si se acredita, previamente, que en el país de origen se otorgan a los chilenos derechos y obligaciones similares a las condiciones de que gozarán estos solicitantes en Chile. Igual exigencia deberá cumplirse para adquirir una concesión existente. La infracción al cumplimiento de esta condición significará la caducidad de pleno derecho de la concesión (S: 02, 01/10/97, 692, énfasis agregado) ${ }^{9}$.

${ }^{9}$ Los dos primeros incisos del Art. $9^{\circ}$ aprobado por la Comisión quedaron así: "En los casos en que la ley permita que el propietario de un medio de comunicación social sea persona natural, ésta deberá tener domicilio en el país y no estar procesada ni haber sido condenada por delito que merezca pena aflictiva. Tratándose de personas jurídicas, éstas deberán estar constituidas en 
El proyecto se dirigió a la Sala del Senado para su discusión en particular. La regla de reciprocidad en el inciso tercero del Art. 9, recién transcrita, fue aprobada por ella. Como se le habían introducido modificaciones al proyecto aprobado por la Cámara de Diputados en primer trámite, debió volver a esta Cámara en tercer trámite.

\subsection{Cámara de Diputados, tercer trámite constitucional}

\subsubsection{Comisión de Constitución, Justicia y Reglamento, y Sala}

Ya en esta Comisión, nuevamente ocurrió algo interesante con la regla de reciprocidad que había introducido el Senado: la Comisión se opuso a ella por unanimidad y recomendó rechazar el artículo que el Senado aprobó "básicamente, con el fin de poder incorporar una norma que evite que la exigencia de 'reciprocidad' lleve al país a vulnerar los compromisos internacionales contraídos con la Organización Mundial de Comercio" (CD: 08, 20/10/99, 1034) ${ }^{10}$. En el mismo sentido, el diputado Zarko Luksic, miembro de la Comisión, explicó a la Sala:

En esta materia, queremos reciprocidad con los países con los cuales existan convenios en materia de propiedad de los medios de comunicación social. O sea, si los venezolanos

Chile o tener agencia que las autorice para operar en Chile, y tener domicilio en el país. Su presidente, administradores o representantes legales deberán ser chilenos y no estar procesados ni haber sido condenados por delito que merezca pena aflictiva. En ambos casos, el auto de procesamiento por delito que merezca pena aflictiva suspenderá al afectado, de inmediato y por el tiempo que se mantenga, de cualquiera función o actividad relativa a la administración del medio y de toda función periodística.

La individualización del propietario o titular de la concesión o permiso, según el caso, deberá mantenerse estrictamente al día, como también, tratándose de personas jurídicas, los nombres de sus socios y el registro de accionistas, los nombres de sus representantes legales y las copias de los documentos que acrediten su constitución y estatutos, sus modificaciones y los mandatos correspondientes, según corresponda. Esta información será pública y deberá estar permanentemente a disposición de cualquier persona en el domicilio social".

${ }^{10}$ Los integrantes de la Comisión fueron los diputados Sergio Elgueta (Pdte.), Francisco Bartolucci, Juan Bustos, Alberto Cardemil, Juan Antonio Coloma, Aldo Cornejo, Alberto Espina, Pía Guzmán, Enrique Krauss, Zarko Luksic, Sergio Ojeda, Aníbal Pérez, Laura Soto e Ignacio Walker (CD: 08, 20/10/99). 
o mexicanos tienen interés en participar en la propiedad y dirección de esos medios, queremos que los inversionistas chilenos también tengan en los países de los solicitantes las mismas garantías y derechos que estamos otorgando a los extranjeros. Creemos necesario elaborar un precepto que establezca reciprocidad entre los derechos y facultades que otorga Chile y los que conceden los países extranjeros. Por lo tanto, rechazamos la modificación, con el objeto de mejorarla (CD: 14, 11/11/99, 1084).

La Sala aprobó este rechazo y el proyecto pasó a Comisión Mixta.

\subsection{Comisión Mixta}

Quedó registrado que ante esta Comisión el Ministro Secretario General de Gobierno, Claudio Huepe, explicó que, en conjunto con el Ministerio de Relaciones Exteriores, estudiaron la posibilidad de incorporar un nuevo inciso destinado a evitar que se produzca el riesgo advertido por la Cámara de Diputados. Sin embargo, el senador Hernán Larraín afirmó que de producirse algún conflicto que involucre compromisos contraídos por el Estado en el marco de los mencionados instrumentos internacionales, serán los tribunales los llamados a resolver. En todo caso, estimó adecuado mantener la regla de reciprocidad tal como lo plantea la norma. Así lo hizo la Comisión Mixta (CM: 50, 08/05/2000, 1177).

La Sala de la Cámara de Diputados, sin embargo, rechazó la propuesta de la Comisión (CD: 52, 16/05/2000, 1204). El Senado, por su parte, la aprobó (S: 02, 07/06/2000, 1216). El Presidente de la República envió un veto aditivo (CD: $28,16 / 08 / 2000,1260$ ), cuyo texto fue aprobado por la Cámara de Diputados y el Senado, previo informe favorable de sus respectivas Comisiones de Constitución, Legislación y Justicia. Sin embargo, nunca se tocó el tercer inciso del Art. 9 del proyecto, con la regla de reciprocidad según la había aprobado la Comisión Mixta, la que, básicamente, era la versión aprobada por el Senado en segundo trámite. Así se estableció en el punto que nos interesa la Ley 19.733, promulgada el 18/05/01 y publicada en el Diario Oficial el 04/06/01. Su Art. $9^{\circ}$ quedó, finalmente, así:

En los casos en que la ley permita que el propietario de un medio de comunicación social sea una persona natural, ésta 
deberá tener domicilio en el país y no haber sido condenada por delito que merezca pena aflictiva. Tratándose de personas jurídicas, éstas deberán tener domicilio en Chile y estar constituidas en el país o tener agencia autorizada para operar en territorio nacional. Su presidente y sus administradores o representantes legales deberán ser chilenos y no haber sido condenados por delito que merezca pena aflictiva. La condena a la pena señalada hará cesar al afectado, de inmediato, en toda función o actividad relativa a la dirección, administración o representación en el medio de comunicación social en que la desempeñe.

Todo medio de comunicación social deberá proporcionar información fidedigna acerca de sus propietarios, controladores directos o indirectos, arrendatarios, comodatarios o concesionarios, según fuere el caso. Si ellos fueren una o más personas, dicha información comprenderá la que sea conducente a la individualización de las personas naturales y jurídicas que tengan participación en la propiedad o tengan su uso, a cualquier título. Asimismo, comprenderá las copias de los documentos que acrediten la constitución y estatutos de las personas jurídicas que sean socias o accionistas, salvo en los casos de sociedades anónimas abiertas, así como las modificaciones de los mismos, según correspondiere. La referida información será de libre acceso al público y deberá encontrarse permanentemente actualizada y a su disposición en el domicilio del respectivo medio de comunicación social y de las autoridades que la requieran en el ejercicio de sus competencias.

Las concesiones para radiodifusión sonora de libre recepción solicitadas por personas jurídicas con participación de capital extranjero superior al diez por ciento, sólo podrán otorgarse si se acredita, previamente, que en su país de origen se otorga a los chilenos derechos y obligaciones similares a las condiciones de que gozarán estos solicitantes en Chile. Igual exigencia deberá cumplirse para adquirir una concesión ya existente. La infracción al cumplimiento de esta condición significará la caducidad de pleno derecho de la concesión.

Hasta aquí la historia del establecimiento de la regla de reciprocidad. Es una regla muy excepcional respecto de la regulación de telecomunicaciones, en general, y de la radiodifusión en particular, porque ni la primera ni la radiodifusión televisiva la contemplan. ¿Por qué sólo 
a la radio y no a la TV, si ambas son radiodifusión masiva? Más bien parece el resultado exitoso de un grupo de interés, la ARCHI, que puede haberse concebido originalmente como un mecanismo para competir de igual a igual en el extranjero, pero que en la práctica opera como barrera de entrada. Además, la regla nunca fue concebida como un mecanismo para el pluralismo, como sí otros de la Ley de Prensa (Arts. $3^{\circ}$, $4^{\circ}$ y $\left.38^{\circ}\right)$.

Todo lo anterior no puede sino conducir a una interpretación restringida de la regla. Y esta restricción debe aplicarse a la estructura de propiedad de las sociedades concesionarias de radiodifusión sonora con participación de capital extranjero. De dicha estructura sólo debe considerarse la participación inmediata, el control directo. Las razones se desarrollan en la sección siguiente.

\section{Sentido}

Cinco son las razones que justifican dicha interpretación restringida:

- Como a toda regla excepcional, cabe darle a la regla de reciprocidad un sentido restringido.

- Como es, más encima, una regla excepcional cuya justificación no es evidente, sino que más parece una excepción arbitraria, doble es la razón para interpretarla restringidamente.

- El contexto en que se desarrolló la historia fidedigna del establecimiento de la Ley de Prensa, sugiere darle una interpretación restringida: cuando los colegisladores quisieron regular el control indirecto sobre la propiedad de una persona jurídica titular de una concesión, así lo dispusieron expresamente.

- La interpretación restringida ha sido desplegada por la práctica del regulador sectorial MTT-Subtel, el único competente - esto nadie lo discute - para fiscalizar la regla de reciprocidad. Dicho regulador sectorial ha venido desplegando esta interpretación restringida en perfecta consonancia con lo dispuesto por la Contraloría General de la República (CGR) y lo ha hecho, además, reconociendo el carácter vinculante que ésta tiene para dicho regulador. Esta práctica regulatoria envuelve lo que en el derecho administrativo se llama "principio de la confianza legítima", que 
tiene una lógica parecida a lo que en la doctrina de derecho privado se denomina "acto propio". Es decir, una persona u órgano no puede contradecir el sentido de las decisiones que ha venido tomando, a menos que surjan hechos que así lo justifiquen fundadamente.

- La incorporación de Chile a la OCDE el año pasado viene a reforzar la interpretación restringida. Y no sólo eso: esta incorporación, así como el contexto internacional en el que se ha venido insertando Chile, sugieren que los colegisladores inicien un proceso legislativo destinado a derogar la regla de reciprocidad.

En lo que sigue, se desarrollan estas razones.

\subsection{Regla de excepción}

Es un verdadero lugar común jurídico decir que las reglas que hacen excepción a la regla general, deben interpretarse restringidamente. Interpretarla extensivamente equivaldría a transformarla en regla general y no, precisamente, en excepción.

La regla de reciprocidad para la propiedad de la radiodifusión sonora hace excepción a varias reglas generales - algunas bastante fundamentales, además - del sistema jurídico chileno. La raíz de esto es que la Constitución, por regla general, se refiere a "personas" sin distinguir sin son nacionales y extranjeros. Para algunas cosas lo hace, por supuesto, como cuando regula el derecho a voto, pero no cuando regula el grueso de los derechos fundamentales, entre ellos, la igualdad ante la ley, el derecho a desarrollar cualquier actividad económica y la libertad para adquirir toda clase de bienes. Esta noción viene desde los albores de la República. En sus Arts. 14 y 57, el Código Civil dice: "La ley es obligatoria para todos los habitantes de la República, inclusos los extranjeros" y "La ley no reconoce diferencias entre el chileno y el extranjero en cuanto a la adquisición y goce de los derechos civiles que regla este Código".

Hay excepciones, por supuesto. El propio Código Civil plantea varias. Por ejemplo, su Art. $1.210 \mathrm{~N}^{\circ} 10$, prohíbe que extranjeros no domiciliados en Chile sean testigos de testamentos solemnes otorgados en Chile. Hay otras excepciones más contemporáneas, por supuesto, como lo dispuesto en el Art. $14^{\circ}$ de la Ley 18.892, Ley de Pesca, y Art. 
$11^{\circ}$ del Decreto-Ley 2.222 de 1998, Ley de Navegación. Estas disposiciones exigen que para la matrícula de las naves su propietario sea chileno. Algo parecido dispone el Art. $38^{\circ}$ de la Ley 18.916, Código Aeronáutico, para la matrícula de las aeronaves. En estas excepciones, sin embargo la ley es clara en el sentido de señalar que, para los efectos de distinguir entre nacionales y extranjeros, la propiedad comprometida sólo debe ser considerada desde el punto de vista del control directo.

Sólo en un caso excepcional, la ley chilena se refiere al control indirecto sobre la propiedad, y lo hace expresamente. Se trata del Decreto-Ley 1.939 de 1977, que establece Normas sobre Adquisición, Administración y Disposición de Bienes del Estado. Los dos primeros incisos de su Art. $7^{\circ}$ disponen:

Por razones de interés nacional se prohíbe adquirir el dominio y otros derechos reales o ejercer la posesión o tenencia de bienes raíces situados total o parcialmente en las zonas del territorio nacional, actualmente declaradas fronterizas en virtud del decreto con fuerza de ley $\mathrm{N}^{\circ} 4$, de 1967, del Ministerio de Relaciones Exteriores, a los nacionales de países limítrofes salvo que medie la autorización prevista en el inciso tercero del presente artículo.

La prohibición a que se refiere el inciso anterior se extenderá a las sociedades o personas jurídicas con sede principal en el país limítrofe, o cuyo capital pertenezca en un $40 \%$ o más a nacionales del mismo país o cuyo control efectivo se encuentre en manos de nacionales de esos países. Esta disposición no regirá respecto de los bienes raíces a que se refiere el artículo 19 de la ley $\mathrm{N}^{\circ}$ 19.420. El Presidente de la República, mediante decreto supremo fundado en razones de interés nacional, podrá eximir, nominativa y expresamente, a nacionales de países limítrofes, de la prohibición precedente y autorizarlos para adquirir o transferir el dominio $u$ otros derechos reales a la posesión o tenencia de uno o más inmuebles determinados, situados en zonas fronterizas. (Subrayado en cursivas agregado).

Al referirse al "control efectivo" de la propiedad por parte de nacionales extranjeros, la disposición recién citada autoriza, expresamente, a descorrer el "velo" de la correspondiente malla societaria. Y para esto esgrime razones de seguridad nacional que podrían justificar esta doble excepcionalidad: distinción entre nacionales y extranjeros para 
efectos de la propiedad, por una parte, y necesidad de atender al control indirecto de la propiedad, por la otra.

La excepcionalidad de la regla de reciprocidad para la radiodifusión sonora, en cambio, no parece tener razón alguna que la justifique.

\subsection{Excepción arbitraria}

Como se vio más arriba, uno de los objetivos originales del proyecto para una nueva Ley de Prensa en 1993 fue eliminar el requisito de nacionalidad chilena para la propiedad de los medios de comunicación que entonces se exigía. Este esfuerzo era coherente con las dos legislaciones vinculadas a la legislación de prensa, vigentes a la época: la Ley General de Telecomunicaciones de 1982 (Ley 18.168) y la Ley de Televisión de 1989 (Ley 18.838), reformada en 1992. Ambos cuerpos legales no exigían nacionalidad a la propiedad, sino que sólo a la administración de las personas jurídicas titulares de concesiones de radiodifusión televisiva y de otros servicios de telecomunicaciones que requieren de concesión como título habilitante. Esto, para el solo efecto de garantizar la posibilidad de hacer efectiva la responsabilidad por ilícitos cometidos en el ejercicio de las respectivas concesiones.

Es más, en 1994, durante el segundo año de la tramitación del proyecto de Ley de Prensa, los colegisladores reformaron mediante la Ley 19.277 , los incisos primeros de los Arts. $2^{\circ}$ y $8^{\circ}$ de la Ley de Telecomunicaciones, disponiendo, respectivamente: "Todos los habitantes de la República tendrán libre e igualitario acceso a las telecomunicaciones y cualquier persona podrá optar a las concesiones y permisos en la forma y condiciones que establece la ley", y "Para todos los efectos de esta ley, el uso y goce de frecuencias del espectro radioeléctrico será de libre e igualitario acceso por medio de concesiones, permisos o licencias de telecomunicaciones, especialmente temporales, otorgadas por el Estado".

Conociendo del proyecto de Ley de Prensa, la Cámara de Diputados aprobó el proyecto en primer trámite constitucional de acuerdo a estas consideraciones. Llegado al Senado, también se expresó que los requisitos de nacionalidad vinculados a la propiedad de los medios de comunicación correspondían a "épocas pasadas"11. Pero, no obstante

${ }^{11}$ Para la cita completa de este punto del Primer Informe de la Comisión de Constitución, Legislación, Justicia y Reglamento del Senado, véase supra, p. 105. 
estas declaraciones, el rumbo del proceso legislativo en este punto cambió de dirección tras la intervención de tres entes gremiales: ARCHI, ANATEL y ANP, y la rápida acogida que su solicitud por una regla de reciprocidad tuvo en el Senado ${ }^{12}$.

Originalmente, la solicitud de estos tres entes gremiales, si bien se oponía al impulso original del proyecto en el sentido de desvincular nacionalidad y propiedad de los medios de comunicación, guardaba cierta coherencia interna al aplicarse a ambos tipos de radiodifusión: sonora y televisiva; y con un fin declarado aparentemente razonable: permitir a los chilenos operar medios de comunicación en los países a los cuales la economía chilena se estaba abriendo.

Pero al final la coherencia se perdió, pues la regla fue dejada exclusivamente para la radiodifusión sonora y no para la televisiva, no obstante estar ambas sometidas a un régimen de concesiones. Como se vio más arriba, en toda la historia del establecimiento de la Ley de Prensa hay sólo un atisbo de explicación para esta diferencia. Sin embargo, es una explicación errada porque no se condecía, ni se condice, con la realidad. Fue hecha por la ARCHI en su primera comunicación al Senado en 1996. Según ella, la radio debería tener un tratamiento en materias de propiedad extranjera distinto a la prensa escrita y la TV. Esto, pues la radio sería un medio "fundamentalmente estratégico" y "de gran penetración cultural"13.

La verdad es que, en esto, la radio no se diferencia en nada de la TV. Ambas tienen una amplia cobertura nacional, y su penetración política y cultural es parecida. De hecho, los estudios disponibles revelan que las personas en Chile se informan más por la TV que por la radio. Así, por ejemplo, una encuesta del CEP de 1997, es decir, de la época en que se estaban discutiendo estas materias en la Comisión de Constitución, Legislación y Justicia del Senado, mostraba que el 73\% de los encuestados afirmaba haber "utilizado en la última semana la radio para informarse sobre noticias del acontecer nacional e internacional". Por su parte, el $87 \%$ afirmaba haber utilizado la $\mathrm{TV}^{14}$. En el mismo sentido, en una encuesta posterior del Consejo Nacional de Televisión (2005) sobre las fuentes que la población usa para informarse acerca de a 110 .

${ }^{12}$ Para las intervenciones de estos entes gremiales, véase supra, pp. 107

${ }^{13}$ La cita completa en pp. 107 y 108, supra.

${ }^{14}$ En Centro de Estudios Públicos (1997). 
lo que ocurre en su ciudad, Chile y el mundo, el 79,8\% dijo informarse mediante la televisión, y sólo el 5,9\% mediante la radio ${ }^{15}$. Al respecto, se ha afirmado: "La evidencia sugiere que ella [la televisión] ha pasado a ser el medio más importante a través del cual el público chileno conoce y entiende los principales sucesos que ocurren en el país y en el mundo"16. En la misma perspectiva: "Para concluir, podemos decir que en un contexto de alta competitividad, la información televisiva se ha vuelto cada vez más central"17.

No obstante esta evidencia y el hecho de que tanto la radio como la TV usan espectro radioeléctrico, la regla de reciprocidad quedó finalmente reservada para la radiodifusión sonora y no para la televisiva. Esta última fue excluida de la regla en el Senado sin explicación alguna, como vimos más arriba ${ }^{18}$.

Esta regla, entonces, envuelve una doble excepción: a la regla general en el sentido de que la propiedad de las cosas en Chile está abierta a personas, sin distinguir si son nacionales o extranjeros y, además, se circunscribe a la radiodifusión sonora y no a la radiodifusión en general. Esto último no tiene una justificación firme. Al carecer de ella, deviene arbitraria. Doble razón, entonces, para interpretarla restringidamente. Esta doble razón, con todo, no es la única para dicha interpretación. También lo es el modo en que pareciera los colegisladores formularon la regla de reciprocidad y el contexto que tuvieron a la vista.

\subsection{Contexto}

Al tiempo de discutirse en el Congreso el proyecto que desembocó en la Ley de Prensa, la distinción entre control directo e indirecto sobre la propiedad era, por supuesto, una cuestión conocida y reconocida por el sistema jurídico.

Así, por ejemplo, las legislaciones de pesca, navegación, aeronavegación y sobre adquisición, administración y disposición de bienes del Estado, que vimos más arriba, usan la distinción. Estas legislaciones estaban vigentes al momento de discutirse el proyecto que se transformaría en la Ley de Prensa en 2001. Lo mismo puede decirse de otras

\footnotetext{
15 En Consejo Nacional de Televisión (2005).

${ }^{16}$ Marín (2007), p. 42.

17 Jiménez, Argandoña y Torres (2007), p. 159.

${ }^{18}$ Véase supra, p. 111.
} 
dos importantes legislaciones: de Mercado de Valores (Ley 18.045) y de Sociedades Anónimas (Ley No 18.046), ambas de 1981.

Estas leyes contienen la distinción entre control directo e indirecto sobre la propiedad, expresada en conceptos a los que otras legislaciones suelen remitirse. Así, por ejemplo, la definición de "grupo empresarial" que hace el Art. $96^{\circ}$ de la Ley de Mercado de Valores:

[...] conjunto de entidades que presentan vínculos de tal naturaleza en su propiedad, administración o responsabilidad crediticia, que hacen presumir que la actuación económica y financiera de sus integrantes está guiada por los intereses comunes del grupo o subordinada a éstos, o que existen riesgos financieros comunes en los créditos que se les otorgan o en la adquisición de valores que emiten.

Forman parte de un mismo grupo empresarial:

a) Una sociedad y su controlador;

b) Todas las sociedades que tienen un controlador común, y este último, y

c) Toda entidad que determine la Superintendencia [de Valores y Seguros] considerando la concurrencia de una o más de las siguientes circunstancias:

1. Que un porcentaje significativo del activo de la sociedad está comprometido en el grupo empresarial, ya sea en la forma de inversión en valores, derechos en sociedades, acreencias o garantías;

2. Que la sociedad tiene un significativo nivel de endeudamiento y que el grupo empresarial tiene importante participación como acreedor o garante de dicha deuda;

3. Que la sociedad sea miembro de un controlador de algunas de las entidades mencionadas en las letras a) o b), cuando este controlador corresponda a un grupo de personas y existan razones fundadas en lo dispuesto en el inciso primero para incluirla en el grupo empresarial, y 4. Que la sociedad sea controlada por uno o más miembros del controlador de alguna de las entidades del grupo empresarial, si dicho controlador está compuesto por más de una persona, y existan razones fundadas en lo dispuesto en el inciso primero para incluirla en el grupo empresarial.

Tanto o más útil aquí es la definición de "controlador" que hace en su Art. $97^{\circ}$ : 
Es controlador de una sociedad toda persona o grupo de personas con acuerdo de actuación conjunta que, directamente o a través de otras personas naturales o jurídicas, participa en su propiedad y tiene poder para realizar alguna de las siguientes actuaciones:

a) Asegurar la mayoría de votos en las juntas de accionistas y elegir a la mayoría de los directores tratándose de sociedades anónimas, o asegurar la mayoría de votos en las asambleas o reuniones de sus miembros y designar al administrador o representante legal o a la mayoría de ellos, en otro tipo de sociedades, o

b) Influir decisivamente en la administración de la sociedad.

Cuando un grupo de personas tiene acuerdo de actuación conjunta para ejercer alguno de los poderes señalados en las letras anteriores, cada una de ellas se denominará miembro del controlador.

En las sociedades en comandita por acciones se entenderá que es controlador el socio gestor.

Lo mismo puede decirse del primer inciso de su Art. $100^{\circ}$, que define las "personas relacionadas":

Son relacionadas con una sociedad las siguientes personas:

a) Las entidades del grupo empresarial al que pertenece la sociedad;

b) Las personas jurídicas que tengan, respecto de la sociedad, la calidad de matriz, coligante, filial o coligada, en conformidad a las definiciones contenidas en la ley $\mathrm{N}^{\circ} 18.046$;

c) Quienes sean directores, gerentes, administradores, ejecutivos principales o liquidadores de la sociedad, y sus cónyuges o sus parientes hasta el segundo grado de consanguinidad, así como toda entidad controlada, directamente o a través de otras personas, por cualquiera de ellos, y

d) Toda persona que, por sí sola o con otras con que tenga acuerdo de actuación conjunta, pueda designar al menos un miembro de la administración de la sociedad o controle un $10 \%$ o más del capital o del capital con derecho a voto si se tratare de una sociedad por acciones.

Hay varios otros ejemplos en la Ley de Mercado de Valores, que muestran la distinción entre control directo e indirecto de la propiedad, y el carácter expreso que éste siempre tiene. Por ejemplo, su Art. $40^{\circ} \mathrm{N}^{\circ} 5$ : 
Ningún corredor, en forma individual o conjuntamente con personas relacionadas, podrá poseer, directa o indirectamente, más del $10 \%$ de la propiedad de una bolsa de valores. (Subrayado en cursivas agregado).

El inciso primero de su Art. $54^{\circ}$ :

Toda persona que, directa o indirectamente, pretenda tomar el control de una sociedad anónima que haga oferta pública de sus acciones, cualquiera sea la forma de adquisición de las acciones, comprendiéndose incluso la que pudiese realizarse por suscripciones directas o transacciones privadas, deberá previamente informar tal hecho al público en general. (Subrayado en cursivas agregado).

\section{Y su Art. $232^{\circ}$ :}

En caso que una sociedad administre más de un tipo de fondo, las inversiones de éstos en acciones de sociedades anónimas abiertas y otras acciones inscritas en el Registro de Valores de la Superintendencia respectiva; en acciones de transacción bursátil, emitidas por sociedades o corporaciones extranjeras cuya emisión haya sido registrada como valor de oferta pública en el extranjero; en valores convertibles en acciones de una sociedad; en cuotas de fondos de inversión; en cuotas de fondos de inversión extranjeros cerrados; y en cuotas de fondos mutuos, consideradas en conjunto, no podrán permitir el control directo o indirecto del respectivo emisor. (Subrayado en cursivas agregado).

La Ley sobre Sociedades Anónimas, por su parte, es también pródiga en conceptos que sugieren la distinción entre control directo e indirecto. Así, por ejemplo, el Art. $44^{\circ}$ inciso tercero se refiere expresamente al control indirecto para calificar el "interés" de un director:

Se entiende que existe interés de un director en toda negociación, acto, contrato u operación en la que deba intervenir en cualquiera de las siguientes situaciones: (i) él mismo, su cónyuge o sus parientes hasta el segundo grado de consanguinidad o afinidad; (ii) las sociedades o empresas en las cuales sea director o dueño, directamente o a través de otras personas naturales o jurídicas, de un $10 \%$ o más de su capi- 
tal; (iii) las sociedades o empresas en las cuales alguna de las personas antes mencionadas sea director o dueño, directo $o$ indirecto, del 10\% o más de su capital, y (iv) el controlador de la sociedad o sus personas relacionadas, si el director no hubiera resultado electo sin los votos de aquél o aquéllos. (Subrayado en cursivas agregado).

Esta distinción entre control directo e indirecto se puede advertir tras lo dispuesto en sus Arts. $86^{\circ}$ y $87^{\circ}$ que definen, respectivamente, sociedades "filiales" y "coligadas":

Art. 86. Es sociedad filial de una sociedad anónima, que se denomina matriz, aquella en la que ésta controla directamente o a través de otra persona natural o jurídica más del $50 \%$ de su capital con derecho a voto o del capital, si no se tratare de una sociedad por acciones o pueda elegir o designar o hacer elegir o designar a la mayoría de sus directores o administradores.

La sociedad en comandita será también filial de una anónima, cuando ésta tenga el poder para dirigir u orientar la administración del gestor.

Art. 87. Es sociedad coligada con una sociedad anónima aquella en la que ésta, que se denomina coligante, sin controlarla, posee directamente o a través de otra persona natural o jurídica el $10 \%$ o más de su capital con derecho a voto o del capital, si no se tratare de una sociedad por acciones, o pueda elegir o designar o hacer elegir o designar por lo menos un miembro del directorio o de la administración de la misma.

La sociedad en comandita será también coligada de una anónima, cuando ésta pueda participar en la designación del gestor o en la orientación de la gestión de la empresa que éste ejerza.

Y su Art. $88^{\circ}$ deja ver con claridad la distinción entre control directo e indirecto a propósito de la "participación recíproca" (no olvidar que en la regla de reciprocidad el concepto de "participación de capital extranjero" es importante):

Art. 88. Las sociedades filiales y coligadas de una sociedad anónima no podrán tener participación recíproca en sus respectivos capitales, ni en el capital de la matriz o de la coligante, ni aun en forma indirecta a través de otras personas naturales o jurídicas. 
La participación recíproca que ocurra en virtud de incorporación, fusión, división o adquisición del control por una sociedad anónima, deberá constar en las respectivas memorias y terminar en el plazo de un año desde que el evento ocurra.

Esta prohibición también regirá aun cuando la matriz o la coligante, en su caso, no fuere una sociedad anónima, siempre que sí lo sea a lo menos una de sus filiales o coligadas. Para estos efectos y para los del artículo siguiente, se aplicarán los conceptos precisados en los artículos 86 y 87 de esta ley.

Todo hace suponer que los colegisladores a cargo del estudio del proyecto de Ley de Prensa conocían la distinción entre control directo e indirecto sobre la propiedad de una persona jurídica. De hecho, la mencionaron expresamente al dar forma al inciso segundo del Art. $9^{\circ}$, cuyo inciso tercero contiene la regla de reciprocidad. Se hace para determinar la información fidedigna que, respecto de su propiedad, todo medio de comunicación debe poner a disposición del público ${ }^{19}$.

Al redactar el inciso tercero con la regla de reciprocidad, sin embargo, los colegisladores omitieron la distinción entre capital directo e indirecto y hablaron sólo de "personas jurídicas con participación de capital extranjero". Es muy extraño que, habiendo querido incluir el control indirecto además del directo para aplicar la regla de reciprocidad, no lo hubieran dicho expresamente así, tal como lo habían hecho en el inciso segundo del mismo Art. 9. Todo indica, por tanto, que el sentido de la ley aquí es que la regla se aplica sólo al control directo, restringidamente.

${ }^{19}$ Dispone este inciso segundo: "Todo medio de comunicación social deberá proporcionar información fidedigna acerca de sus propietarios, controladores directos o indirectos, arrendatarios, comodatarios o concesionarios, según fuere el caso. Si ellos fueren una o más personas, dicha información comprenderá la que sea conducente a la individualización de las personas naturales y jurídicas que tengan participación en la propiedad o tengan su uso, a cualquier título. Asimismo, comprenderá las copias de los documentos que acrediten la constitución y estatutos de las personas jurídicas que sean socias o accionistas, salvo en los casos de sociedades anónimas abiertas, así como las modificaciones de los mismos, según correspondiere. La referida información será de libre acceso al público y deberá encontrarse permanentemente actualizada y a su disposición en el domicilio del respectivo medio de comunicación social y de las autoridades que la requieran en el ejercicio de sus competencias". (Subrayado en cursivas agregado). 
Ello significa que el capital extranjero de la persona jurídica que es aquí relevante es el inmediatamente ingresado al país por medio, por ejemplo, de las operaciones de "cambios internacionales" que autoriza la Ley 18.840, Orgánico-Constitucional del Banco Central, y por el llamado "Compendio de Normas de Cambios Internacionales" que el Consejo de dicho banco ha dictado. El Capítulo XIV de éste define los "aportes de capital" provenientes del exterior:

2.4 Aportes de Capital: Cualquier acto, convención o contrato en virtud del cual una parte destina divisas provenientes del exterior, o el producto de su liquidación en el país, a constituir o aumentar el capital de una persona jurídica, domiciliada en Chile, como asimismo la capitalización en ésta, de obligaciones en moneda extranjera que ella haya contraído en o con el exterior. Para los efectos de este Capítulo, se autoriza que los aportes de capital puedan enterarse en acciones o derechos sociales de sociedades constituidas en el exterior, debiendo entregarse al Banco Central de Chile la información que se indica en el Capítulo XIV del Manual. En este caso, la remesa del capital, dividendos o utilidades deberá efectuarse siempre en divisas.

Asimismo, se considerarán como aportes de capital para efectos de este Capítulo, el capital aportado por un inversionista extranjero a sociedades constituidas de acuerdo con lo dispuesto en el artículo $41 \mathrm{D}$ de la Ley sobre Impuesto a la Renta, sea que el capital se entere en acciones o en derechos sociales de sociedades domiciliadas en el extranjero de propiedad de personas sin domicilio ni residencia en Chile, valorados todos ellos a su precio bursátil o de libros, según corresponda, o de adquisición en ausencia del primero.

También se considerará como aporte de capital la reinversión de utilidades que efectúe un inversionista extranjero, acogido al Estatuto de la Inversión Extranjera contenido en el Decreto Ley $\mathrm{N}^{\circ} 600$ de 1974, y sus modificaciones, siempre que dicho inversionista renuncie en forma previa e irrevocable al derecho a remesar las respectivas utilidades de acuerdo al citado régimen especial, en los términos y en las condiciones que establezca el Comité de Inversiones Extranjeras. El cumplimiento de estos requisitos se acreditará mediante la comunicación respectiva que dicho Comité remita al $\mathrm{Banco}^{20}$.

${ }^{20}$ Véase el Capítulo XIV en http://www.bcentral.cl/normativa/cambiointernacional/compendio-normas/pdf/CapXIV.pdf. 
La "participación de capital extranjero" en la persona jurídica titular de una concesión de radiodifusión sonora, a que se refiere la regla de reciprocidad, tiene que ver con el capital que, desde el exterior, es aportado a esa persona jurídica, ya sea a través de las normas del Capítulo XIV recién mencionadas, a través del contrato de inversión extranjera regulado por el Decreto Ley 600 de 1974, o a través de los mecanismos de fondos de inversión de capital extranjero que regula la Ley $\mathrm{N}^{\circ} 18.657$ (1987).

La persona jurídica con participación de capital extranjero, mediante alguno de los mecanismos recién mencionados, es la que debe ser titular de la concesión y no aquélla en cuyo capital participa otra persona jurídica cuyo capital fue aportado desde el exterior.

Así es la interpretación restringida que este trabajo postula, una que le interesa el control directo y no el indirecto o "efectivo", como expresamente habla la excepcional ley sobre adquisición de inmuebles en zonas fronterizas, o la Ley de Sociedades Anónimas, que se vieron más arriba. Es la interpretación que han sostenido los dos órganos con competencias claras en relación con la regla de reciprocidad: el MTT-Subtel, órgano administrativo a cargo de las telecomunicaciones, y la CGR, veedor de la legalidad de los órganos administrativos. A continuación, una mirada a la práctica administrativa que sobre el punto han desarrollado.

\subsection{La práctica administrativa}

\subsubsection{La CGR}

El núcleo de esta práctica está constituido por el dictamen $N^{\circ} 1.861$, de 15/01/08. La CGR había sido solicitada por la Cámara de Diputados y, además, por dos diputados en particular (Escobar y Valenzuela), y por la Subtel, a objeto de que se pronunciara sobre la regla de reciprocidad del inciso tercero del Art. 9 de la Ley de Prensa, tantas veces referido.

El contexto de esa solicitud y dictamen fue la compra por parte de GLR Chile Ltda. de la totalidad de las acciones de Iberoamerican Radio Chile S.A. a Claxson Chile S.A. Ese acto y sus partes, sabemos, tienen que ver con los procedimientos administrativos que concluyeron en las Resoluciones Exentas 1533 de 2008 y 6620 de 2011 de la Subtel, a los que se hace referencia más abajo. 
La CGR fue inequívoca al fijar la interpretación restringida, al expresar que la regla de reciprocidad:

[Es] de carácter excepcional y se encuentra sujeta a una doble limitación, tanto respecto de las personas que afecta, como en cuanto a los actos o convenciones sólo es aplicable a aquellas personas jurídicas con participación de capital extranjero superior al diez por ciento que soliciten se les otorgue una concesión de radiodifusión o que se les otorgue una concesión de radiodifusión o se les autorice adquirir una ya otorgada, sin que se pueda extender a las entidades que tengan o ejerzan control sobre dichas personas jurídicas con participación de capital extranjero, ni a otros actos o convenciones distintos al otorgamiento o adquisición de una concesión, para lo cual la ley habría tenido que disponerlo expresamente. (Subrayado en cursivas agregado).

La CGR fue doblemente enfática sobre la interpretación restringida que corresponde dar a la regla. Primero, se aplica sólo respecto del control directo de la persona jurídica titular de la concesión y, segundo, sólo a propósito de dos actos o momentos: otorgamiento o adquisición de la concesión.

Este trabajo se centra básicamente en la primera de las restricciones señaladas, es decir, en la forma restringida de entender la participación de capital extranjero en la persona jurídica titular. La segunda restricción, esto es, la relativa a los actos o momentos a propósito de los cuales cabe preguntarse por la regla, es interesante y se trata más abajo. Esta segunda restricción es también interesante. Ella implica preguntarse si la "renovación" de una concesión de radiodifusión sonora puede entenderse como el "otorgamiento" que señala la regla. Pueden sostenerse ambas cosas, pero este trabajo sugerirá que es más prudente no enredarse en esta discusión y asumir que la "renovación" es un "otorgamiento" para los efectos de la regla. Antes de ir a esto, sin embargo, veamos el papel que ha jugado en esta práctica regulatoria el regulador sectorial MTT-Subtel.

\subsubsection{MTT-Subtel}

Algunos meses después de este dictamen de la CGR, la Subtel resolvió, mediante Resolución Exenta 1.533 de 24/12/08, el procedimien- 
to administrativo que se había iniciado, a la luz de la regla de reciprocidad, respecto de las concesiones que habían sido objeto de la operación de compra de acciones que había autorizado el Tribunal de Defensa de la Competencia (TDLC), operación de compra, sabemos, que tiene que ver con el procedimiento administrativo en el que se pronuncia este trabajo.

La Subtel confirmó el sentido restringido fijado por la CGR para la regla de reciprocidad, en sus dos caras: tanto en relación con el acto o momento a propósito del cual se aplica la regla, como en relación con la estructura de capital de la persona jurídica titular de la concesión. Sobre lo primero, dijo en su resolución:

[D]ebe descartarse la hipótesis de que en la especie haya existido una transferencia, adquisición o cesión directa de una o más concesiones [...] más allá de que hayan podido variar las sociedades que tenían el control accionario de las sociedades titulares de dichas concesiones [...] razón por la cual la operación [de compra de acciones] no requería, en caso alguno, de la autorización previa de esta Subsecretaría $[\ldots]$.

Sin embargo, y siguiendo también el criterio de la CGR, la Subtel reconoció para sí la facultad de fiscalizar el cumplimiento, en todo momento, de la observancia de la regla de reciprocidad.

Sobre lo segundo, es decir, sobre el entendimiento restringido de la estructura de propiedad a efectos de aplicar la regla, la Subtel fue, simplemente, inequívoca:

[E]sta Subsecretaría, para los efectos de determinar la presencia de capital extranjero superior al $10 \%$ [...], no podrá sino restringir su análisis a las personas jurídicas actualmente concesionarias... sin efectuar dicho examen, por tanto, respecto de sus controladoras o matrices ni respecto de las controladoras o matrices de estas últimas... [sino] sólo respecto de aquellas personas jurídicas que tengan verdaderamente la categoría jurídica de "inversores extranjeros" o participen de capital extranjero... no siendo procedente examinar la constitución accionaria o de capital de las sociedades que pudieran ser directa o indirectamente sus matrices o controladoras. (Subrayado en cursivas agregado). 
Por Resolución Exenta 4349 de 14/08/09, la Subtel rechazó los recursos de reposición interpuestos contra su resolución recién citada, y concedió los recursos jerárquicos deducidos subsidiariamente. Conociendo de éstos, el MTT, mediante Resolución Exenta 1341 de 08/03/10, confirmó tanto la forma como el fondo de lo que había resuelto la Subtel, enfatizando el hecho de que en todo momento esta Subsecretaría siguió el criterio restringido que había fijado la CGR.

Y no podría haber sino adoptado esta decisión sobre el precedente establecido por la CGR. Es importante tener presente que el Art. 9 de la Ley $\mathrm{N}^{\circ} 10.336$, Orgánica de la CGR, dispone que los informes que emita el Contralor a petición de cualquier jefe de oficina o servicio "serán obligatorios para los funcionarios correspondientes, en el caso o casos concretos a que se refieran".

Por su parte, y a la luz de la disposición legislativa recién citada, la CGR pronunció el dictamen $\mathrm{N}^{\circ} 28.226$, en el que provee una interesante justificación de la interpretación restringida. Señaló:

\begin{abstract}
La interpretación estricta que se postula como propia de las normas de derecho público debe primero distinguir el contenido de estas normas, de modo que sólo se interpreten restrictivamente aquéllas que se refieren a las atribuciones de los órganos del Estado, en tanto que las que se refieren a derechos, libertades o garantías de las personas, o limiten las potestades estatales, lo sean extensivamente, conforme a los principios que enuncia en la materia la Constitución Política de la República.
\end{abstract}

Es una justificación de la interpretación restringida interesante porque avanza un correcto punto de moralidad política. La regla de reciprocidad aumenta los poderes estatales y disminuye distintas garantías constitucionales, como las de igualdad ante la ley, libre iniciativa económica y libre acceso a las cosas objeto del derecho de propiedad, como las cosas incorporales que son las concesiones. Debe, por tanto, ser interpretada restringidamente ${ }^{21}$.

${ }^{21}$ A este respecto se ha dicho: "[E]l modelo de libertades básicas que desarrolla la nueva Constitución chilena supone que esa máxima se transforme en principio que recorra la actividad educacional, cultural, económica y social. En el fondo, supone que no sean las libertades y garantías las que hay que fundamentar jurídicamente, sino, precisamente y en forma muy cuidado- 
Y, por último, el 30/11/11, por Resolución Exenta $N^{\circ} 6620$, la Subtel resolvió un procedimiento administrativo de fiscalización en el que se estableció expresamente la interpretación restringida.

No obstante todo esto, hay órganos del Estado en Chile que han propuesto para la regla de reciprocidad una interpretación extensiva. Veámoslo.

\subsubsection{La interpretación extensiva y su defensor sin competencia}

La interpretación extensiva está en un considerando del TDLC en su Resolución $\mathrm{N}^{\circ} 20$ de 27/07/07, que se pronunció ante una consulta en el proceso de compra a Claxon S.A. de todas las Iberoamerican Radio Chile S.A., por parte de GLR Chile Ltda. Como se ha dicho, ese procedimiento de consulta ante el TDLC tiene que ver con el procedimiento administrativo que sirve de marco a este trabajo.

Sostuvo el TDLC en su considerando nonagésimo:

A juicio de este Tribunal, se debe hacer presente que las normas de la Ley $\mathrm{N}^{\circ} 19.733$ antes indicadas, respecto de la propiedad o control de concesiones de espectro radioeléctrico, son aplicables no sólo al titular directo de la concesión,

\footnotetext{
sa, las excepciones. Ese solo avance metódico sería un paso enorme hacia un régimen constitucional efectivo", Barros (1981), p. 33. Y, en el mismo sentido: "[L]a Constitución no sólo impone toda esta batería de limitaciones a la Administración-aparato, sino que impide que las mismas sean extendidas en bloque a los particulares por el legislador ordinario. En efecto, muchas de las limitaciones examinadas chocan frontalmente con algunos de los derechos y libertades reconocidos a los particulares en el Título primero de la propia Constitución. Piénsese, por ejemplo, en el principio de legalidad — entendido como vinculación positiva - : afirmar que los particulares sólo podrán hacer aquello que la Ley les permita expresamente chocaría, por de pronto, con el principio de libre desarrollo de la personalidad [...] Exigir, a su vez, que los particulares sólo pudieran perseguir con su actuación el interés general contradiría flagrantemente libertades fundamentales como la libertad de empresa... (que legitima y se basa en el ánimo de lucro, el paradigma del interés particular). Extender a los particulares el principio de transparencia vulneraría el derecho fundamental a la intimidad [...] Y así sucesivamente. En general, el carácter servicial, puramente instrumental que la Constitución impone a la Administración-aparato (y que justifica su misma existencia y los miles de millones de euros que cuesta a los contribuyentes) no podría ser predicado de los particulares sin subvertir completamente el Estado de Derecho y de libertades diseñado por la propia Constitución", Mir (2003), p. 80.
} 
sino que a aquellas personas o sociedades que tienen o ejercen control sobre ésta, sea mediante sociedades relacionadas, participación accionaria, acuerdos de control y cualquier otra figura contractual por la que se manifieste dicho control, en la medida que éstos tengan efectos en Chile. De otra forma, tales normas quedarían sin real sentido y aplicación, siendo fácilmente eludibles con la sola figura de la transferencia de acciones entre empresas matrices.

En otras palabras, a juicio del TDLC la regla de reciprocidad se aplica, además, al control indirecto sobre la propiedad de una persona jurídica titular de una concesión de radiodifusión sonora. ¿Por qué? Sólo porque la reciprocidad sería fácilmente eludible. Este es un argumento débil, porque da por supuesto lo que tiene que probar, esto es, da por supuesto que la Ley de Prensa extiende la regla de reciprocidad al control indirecto, esto es lo que, a su juicio, no debería poder eludirse fácilmente. Pero aun cuando este argumento no se comparte, la discusión es relativamente estéril, pues fue el propio TDLC, en el considerando siguiente, el que le restó fuerza a la interpretación extensiva que propuso:

Nonagésimo primero. Que, no obstante lo anterior, esta circunstancia no será considerada en la resolución de esta consulta, dado que su cumplimiento, así como otros requisitos formales establecidos en la LGT, debe ser fiscalizado por la Subsecretaría de Telecomunicaciones y no por este Tribunal, en tanto excede su competencia en un procedimiento de esta naturaleza.

Se trata, por tanto, de una opinión pronunciada por un órgano al margen de su ámbito de competencia. Poca fuerza persuasiva, menos vinculante ${ }^{22}$.

22 En el Anexo 4, infra, se agregan algunos antecedentes que complementan lo dicho aquí sobre la práctica regulatoria de la interpretación restringida y de la debilidad — de fondo y forma - del argumento extensivo del TDLC. Se ilustra el hecho de que el regulador sectorial MTT-Subtel venía otorgando y autorizando adquisiciones de concesiones a personas jurídicas vinculadas a las partes en la operación de compra de las acciones de Iberoamerican Radio Chile S.A. por parte de GLR Chile S.A. En las adquisiciones también se pronunció el TDLC a la luz de lo dispuesto en el Art. $38^{\circ}$ de la misma Ley de Prensa. Nunca el TDLC llamó la atención sobre la regla de reciprocidad del inciso tercero de su Art. $9^{\circ}$, ni solicitó al regulador sectorial MTT-Subtel fiscalizar al respecto. 
Nada ha cambiado desde que se asentó la interpretación restringida de la regla de reciprocidad en la práctica administrativa competente del MTT-Subtel y la CGR. Y así lo entendió, otra vez, el regulador sectorial al dictar las resoluciones exentas que se publicaron en el Diario Oficial los días 12, 13 y 18 del 11/10, mediante las cuales se asignaron concesiones de radiodifusión sonora en procedimientos de renovación de ellas. Esas resoluciones fueron "reclamadas" en los términos del Art. $13 \mathrm{~A}$, dándose inicio al procedimiento administrativo de fiscalización que terminó con la Resolución Exenta $\mathrm{N}^{\circ} 6620$ ya citada.

Lo único nuevo que es relevante aquí, es la incorporación de Chile a la OCDE a fines del año 2010. Este hecho nuevo, sin embargo, en lugar de justificar una revisión de la interpretación restringida que había asentado la práctica administrativa — configurando un caso de lo que se llama "principio de la confianza legítima" por la doctrina del derecho administrativo o "acto propio", por la del derecho privado-, lo que hace es confirmar y reforzar aún más esa interpretación restringida. Igual como lo sugiere el contexto internacional en el que se ha venido insertando Chile, la entrada de Chile a la OCDE justifica la restricción interpretativa. Es más, justifica el inicio por parte de los colegisladores de una reforma para derogar la regla la reciprocidad, según se verá a continuación.

\subsection{El contexto internacional y la incorporación de Chile a la OCDE}

Durante los procedimientos generados por la operación de compra de las acciones de Iberoamerican Radio Chile S.A., consultada al TDLC y tantas veces citada, se reveló lo problemática que resulta la regla de reciprocidad en el contexto de internacionalización que viene experimentando Chile y su economía.

Hace más de un decenio que las autoridades encargadas de ese proceso de internacionalización vienen apuntando la escasa compatibilidad entre la regla de reciprocidad y los compromisos internacionales asumidos por Chile. Así, por ejemplo, el Oficio Ordinario de 14/05/03, de la Dirección General de Relaciones Económicas Internacionales (DIRECON). Éste afirma, textualmente, que la regla:

[...] contraviene compromisos adquiridos por nuestro país, tanto en el Acuerdo General sobre el Comercio de Servicios, instrumento internacional integrante de la Organización Mun- 
dial del Comercio, y suscrito por Chile en 1994 [...] como en el Tratado de Libre Comercio (TLC) suscrito con México en abril de 1988 y plenamente vigente ${ }^{23}$.

El punto central aquí es el mecanismo de la nación más favorecida (NMF) al que se sujetan los miembros de la OMC. En virtud de dicho mecanismo, estos miembros se obligan "a otorgar, de manera inmediata e incondicional, a los servicios y a los proveedores de servicios de cualquier otro Miembro, un trato no menos favorable que el que se concede a los servicios similares y a los proveedores de servicios similares de cualquier otro país", como claramente dice la Direcon en el Oficio citado (subrayado en cursivas en el original). La aplicación de la regla de reciprocidad, al ser un mecanismo de condicionalidad, vulnera el mecanismo de la NMF. El mismo oficio advierte que en el TLC con México no se reservó la posibilidad de establecer restricciones futuras respecto de la nacionalidad del capital sobre concesiones de radiodifusión sonora, "tratamiento que debería hacerse extensivo a los restantes miembros de la OMC por la aplicación del trato de nación más favorecida".

El mismo sentido ha expresado la Subsecretaría de Relaciones Exteriores mediante sus oficios $\mathrm{N}^{\circ} 14.549$, de 27/09/07, y $\mathrm{N}^{\circ} 1.046$ de 25/03/08. Y, también, el Comité de Inversiones Extranjeras en varios Oficios. Por ejemplo, en el Oficio 195, de 31/08/2001, avanzó una conclusión que el tiempo ha demostrado fue premonitoria: "las dificultades administrativas y legales que pudieran derivarse de la aplicación de esta disposición [la regla de reciprocidad] hacen aconsejable restringir su ámbito de aplicación contribuyendo así a la certeza jurídica de actuales y futuros concesionarios".

En el mes de enero de 2010, Chile dio un nuevo paso en el contexto internacional, el que ha extendido la sombra de duda sobre la regla de reciprocidad: su acceso a la $\mathrm{OCDE}^{24}$. El objetivo fundamental de la OCDE es expandir las economías a través de las relaciones entre los Estados y procurar que estas relaciones se establezcan y practiquen de forma no discriminatoria ${ }^{25}$.

${ }^{23}$ Como ya se vio, ésta es una preocupación que se mencionó en la Cámara de Diputados cuando conoció del proyecto de Ley de Prensa. Esta preocupación no la tuvo el Senado. Véase supra p. 112.

24 El acuerdo de acceso de Chile está en: http://www.oecd.org/dataoecd/41/11/44381035.pdf.

${ }^{25}$ El acuerdo constitutivo de la OCDE, de 1960, está en: http://www. oecd.org/document/7/0,3746,en_2649_201185_1915847_1_1_1_1,00.html. 
En tal sentido, Chile se comprometió a expandir la liberalización de la radiodifusión televisiva a todos los miembros de la OCDE:

En relación con la regla chilena que posibilita la liberalización recíproca en las áreas de radiodifusión y registro de embarcaciones de pesca de propiedad extranjera, Chile se compromete a extender a todos los miembros de la OCDE cualquier medida de liberalización que beneficiaría a un Miembro de la OCDE. (Traducción mía). (Subrayado en cursivas agregado, p. 26).

Éste fue un compromiso general asumido en el marco de dos reservas asociadas a la radiodifusión sonora que Chile hizo frente a dos cuerpos normativos obligatorios para los miembros de la OCDE: el "Código de Liberalización de Movimientos de Capital" y la "Tercera Decisión Revisada sobre Trato Nacional".

La primera reserva, relativa a la liberalización de los movimientos de capital, está en el Anexo 2 del Acuerdo de Acceso de Chile y señala:

Chile

Lista A, I/A Inversión directa:

- Por no residentes en el país en cuestión.

Nota: La reserva aplica sólo a: VII) otorgar y usar concesiones para radiodifusión, lo que se limita a empresas con un máximo de $10 \%$ de capital extranjero. (Cursivas en el original, p. 34). (Traducción mía).

La segunda reserva, relativa al trato nacional, está en el Anexo 5 del Acuerdo de Acceso de Chile y señala:

Radiodifusión: se limita el otorgamiento y uso de concesiones a empresas cuya propiedad por parte de extranjeros no supera el $10 \%$, a menos que se autorice lo contrario. (Traducción mía).

Authority: Law 18,168, Official Gazette, 2 October 1982, General Telecommunications Law, Titles I, II and II; Law 18,838, Official Gazette, 30 September 1989. (Cursivas en el original, p. 58). 
Cabe destacar la peculiaridad de estas reservas. Primero, fueron hechas respecto de dos conjuntos normativos específicos: movimiento de capital y trato nacional. Y, segundo, fueron hechas de un modo que no da buena cuenta de la regla de reciprocidad: la primera la presenta simplemente como un techo a la propiedad extranjera (y no como un mecanismo de reciprocidad) y la segunda la presenta como un techo sujeto a una condición no de reciprocidad, sino que a una de autorización, sin especificar si la premisa de esta autorización es el cumplimiento de una reciprocidad, ni ninguna otra. Tercero, la referencia legislativa es equivocada, porque el $10 \%$ de la participación extranjera de la regla está en la Ley de Prensa, como sabemos, y no en la Ley General de Telecomunicaciones, como señala la segunda reserva. Y, cuarto, la reserva frente a la liberalización de los movimientos de capitales se hace respecto de la inversión "directa".

¿Qué pasaría, por ejemplo, con capitales irlandeses que quisieran constituir una persona jurídica para solicitar una concesión de radiodifusión sonora? Irlanda es miembro de la OCDE, como Chile, pero no tiene restricciones de acceso a la radiodifusión sonora basadas en la nacionalidad del capital. ¿Debería aplicarles la regla de reciprocidad a los capitales interesados provenientes de un tercer Estado miembro de la OCDE, como España, por ejemplo? ¿En qué pie quedaría el mecanismo de nación más favorecida (NMF), valorado por la OCDE según lo expresa su política de Tratamiento no discriminatorio para inversionistas locales e internacionales? ${ }^{26}$

Todo este contexto internacional justifica la formación de una voluntad política colegisladora encaminada a derogar la regla de reciprocidad. Y mientras ella no se concrete, provee la justificación al Estado de Chile para adoptar una interpretación restringida a la hora de aplicarla.

\section{Conclusión}

La regla de reciprocidad es una regla difícil, como lo confirman los problemas de interpretación que ha generado. Es una regla excepcional y, además, es de una excepcionalidad que parece arbitraria, no justificada. Este mismo hecho ayuda a explicar, en parte al menos, esos problemas de interpretación.

${ }^{26}$ Véase esta política en http://www.oecd.org/document/29/0,3746,en_3 9048427_39049329_39634141_1_1_1_1,00.html. 
Todo el sistema jurídico chileno y el contexto internacional que para él es relevante, justifican una interpretación restringida y no extensiva de la regla. En este sentido, los dos órganos competentes que se han pronunciado sobre ella — la CGR y el regulador sectorial MTTSubtel—, han desarrollado una interpretación correcta.

El núcleo de esa interpretación, el dictamen $\mathrm{N}^{\circ} 1.861$, de 15/01/08, de la CGR, fijó un sentido doblemente restringido. Por una parte, la regla de reciprocidad mira sólo al control directo de la propiedad de la persona jurídica, sin que se deba descorrer el velo de la malla societaria para indagar sobre el control indirecto (o "efectivo"), y, por la otra, la regla se aplica sólo a propósito de dos momentos o actos: otorgamiento y adquisición de una concesión de radiodifusión sonora.

Como se anunció más arriba, este trabajo se ha concentrado más en la restricción vinculada a la estructura de propiedad y no con la vinculada al momento o acto de su aplicación. Vale la pena ahora decir unas pocas palabras sobre esta última.

Sostener que la regla de reciprocidad se aplica sólo en esos dos momentos va, por supuesto, en el sentido correcto de construir siempre una interpretación restringida. Pero, también, abre algunas interrogantes. Por ejemplo, en el caso respecto del cual este trabajo se pronuncia: la "renovación" de una concesión ¿es o no una hipótesis de aplicación de la regla?

Alguien podría contestar que no, que la renovación no es otorgamiento ni, obviamente, adquisición. Para eso podría basarse en el hecho de que el Art. 8 de la Ley 18.168, en su inciso tercero, usa ambas expresiones en contextos distintos:

Las concesiones se otorgarán a personas jurídicas. El plazo de las concesiones se contará desde la fecha en que el respectivo decreto supremo se publique en el Diario Oficial; será de 30 años para los servicios públicos e intermedios de telecomunicaciones, renovable por períodos iguales, a solicitud de parte interesada; y de 25 años para las concesiones de radiodifusión respecto de las cuales la concesionaria gozará de derecho preferente para su renovación, de conformidad a los términos de esta ley. (Subrayado en cursivas agregado).

Desde este mismo punto de vista literal — que enfatiza la distinción entre estos tres verbos rectores: "otorgar" y "adquirir", por una parte, y "renovar", por la otra—, parece coincidente la práctica desple- 
gada hasta ahora por el regulador sectorial MTT-Subtel en esta materia. Esto, pues sus actos administrativos distinguen entre "otorgar" y "renovar" concesiones de radiodifusión. Comparemos los siguientes decretos, elegidos al azar dentro del último tiempo.

Uno es el Decreto $\mathrm{N}^{\circ} 151$ de 01/07/10, que otorga una concesión de radiodifusión sonora a la Compañía Chilena de Comunicaciones S.A. Su lenguaje es consistente en el nombre del decreto: "Otorga concesión de...", en la primera parte resolutiva: "Otórgase una concesión..." y en la tercera parte resolutiva: "Facúltese a la concesionaria para instalar, operar y explotar la estación...". Otro es el Decreto $N^{\circ} 387$ de 29/10/10, que también "otorga" una concesión de radiodifusión sonora a Radio Corporación S.A. Su lenguaje es, también, consistente, usando los mismos verbos rectores que el decreto recién citado, en los mismos lugares del texto.

En cambio, otro decreto, el $\mathrm{N}^{\circ} 251$ de 02/09/10 usa, en las mismas partes, el siguiente lenguaje también consistente: "Renueva concesión...", "Renuévase por un período de 25 (veinticinco) años...", y "Facúltese a la concesionaria para seguir operando y explotando la estación de..." Y, en el mismo sentido, el Decreto No 24 de 21/02/11 "renueva" una concesión de radiodifusión sonora a Finis Terrae Sociedad Radiodifusora S.A., usando, también, los mismos verbos rectores del decreto recién citado, en los mismos lugares del texto.

Esto, además, podría justificarse en el hecho de que la renovación tiene algo que ni el otorgamiento $\mathrm{y}$, menos, la adquisición tienen: un "derecho preferente" para el titular que quiere renovar ${ }^{27}$.

Por otra parte, sin embargo, es importante tener presente que, como lo señaló también la CGR en el dictamen citado, la regla de reciprocidad debe fiscalizarse durante todo el tiempo de la respectiva concesión:

[...] comoquiera que las exigencias que agregó la ley $\mathrm{N}^{\circ} 19.733$ no sólo se deben cumplir al tiempo de otorgarse la concesión o adquirirse una ya existente, corresponde que la autoridad fiscalice el efectivo cumplimiento de las mismas durante todo el plazo de su vigencia.

${ }^{27}$ Sobre el carácter del acto de otorgamiento de una concesión, en el cual no hay un "derecho preferente", véase Dromi, (1977), p. 389. 
Eso mismo fue reconocido por el regulador sectorial MTTSubtel en la Resolución Exenta $N^{\circ} 1.533$ de 24/12/08, ya citada. ¿Cómo compatibilizar, entonces, el hecho de que la regla de reciprocidad se aplica sólo a propósito del otorgamiento y adquisición de concesiones, por una parte, y el hecho de que debe haber una fiscalización continua de ella por parte del regulador sectorial, por la otra?

Se podría considerar que la renovación de una concesión es una especie de "otorgamiento" de la misma, por lo que es un momento de aplicación de la regla de reciprocidad. $\mathrm{O}$, en cambio, se podría considerar que no, que son actos distintos, pero como la fiscalización de la regla debe ser continua, es un momento adecuado para indagar si la concesión respectiva fue otorgada o adquirida en cumplimiento de la regla.

Por esto, a juicio de este trabajo, no es tan relevante la cara de la interpretación restringida relativa al momento o acto a propósito del cual se aplica la regla. Como la fiscalización debe ser continua, no vale la pena enredarse mucho en este punto. Más práctico es decir que todos los momentos de una concesión - entre ellos el de su renovación - son buenos para fiscalizar, preguntándose si la regla de reciprocidad fue observada al otorgarse o adquirirse dicha concesión.

Más relevante es la cara de la interpretación restringida relativa a la estructura de propiedad de las personas jurídicas titulares de las concesiones de radiodifusión sonora. Este trabajo sostiene que este sentido restringido debe aplicarse al control directo o participación inmediata en la propiedad de las personas jurídicas titulares de las concesiones de radiodifusión sonora. Esto es, sin descorrer el velo de la malla societaria para hurgar "aguas arriba" en busca de capitales de origen extranjero, porque la ley no lo autoriza expresamente. Al no hacerlo, como sí lo hace en otras disposiciones legislativas excepcionales, no cabe presumir la autorización.

Interpretada así la regla, queda claro que los procedimientos administrativos que concluyeron en las Resoluciones Exentas $\mathrm{N}^{\circ} 1533$ de 2008 y 6620 de 2011 de la Subtel, no fueron hipótesis de aplicación de la regla. Salvo el hecho de que en el segundo caso se trata de una renovación, acto que envuelve a las personas jurídicas titulares de las concesiones, en el fondo la situación es la misma que la de la operación de compra de acciones de Iberoamerican Radio Chile S.A. En ambos casos, no hay participación de capital extranjero superior al 10\% en las 
personas jurídicas titulares, tal como ellas lo acreditaron al regulador sectorial MTT-Subtel mediante declaraciones juradas. Al no ser este caso una hipótesis de aplicación de la regla de reciprocidad, es completamente irrelevante aquí la legislación española sobre medios de comunicación y radiodifusión, así como los cambios que pueda haber experimentado desde 2008 a la fecha.

Y en los casos hipotéticos que sí pudiera aplicarse la regla, es decir, cuando la participación directa o inmediata de capital extranjero en la propiedad de la jurídica titular fuera en los hechos superior al 10\%, la regla debe seguir interpretándose restringidamente. ¿Cómo? Exigiendo que la comparación recíproca entre los Estados sea acotada, es decir, sólo restringida al porcentaje de participación de capital extranjero permitido, sin extenderse a otros aspectos posibles como, por ejemplo, la duración de las concesiones.

Pero todo indica que lo más adecuado en el largo plazo es derogar esta regla, sometiendo la radiodifusión sonora a las mismas reglas de la radiodifusión televisiva y de las demás concesiones para servicios de telecomunicaciones. Éstas exigen que la persona jurídica se constituya en Chile y que su administración sea chilena, pero el origen del capital es irrelevante. La Constitución asegura a todas las personas un libre acceso a la propiedad de las cosas. Las limitaciones o requisitos para ejercer este derecho deben estar exigidos por el interés nacional. La regla de reciprocidad es una limitación o requisito para el acceso a la propiedad de las cosas incorporales que son las concesiones de radiodifusión sonora. ¿Está exigida por el interés nacional?

Derogando esta regla no sólo se honraría la disposición constitucional recién citada, sino que también se haría mucho más consistente la situación de nuestro sistema jurídico con las obligaciones y compromisos que el Estado ha asumido en el marco de la OMC, de los tratados de libre comercio y, más recientemente, de la OCDE. Al ingresar a este club, Chile hizo una reserva imperfecta de la regla de reciprocidad por la que, en el campo de la radiodifusión sonora, se está eximiendo injustificadamente de cumplir con los valiosos compromisos de libertad de comercio e igualdad de trato que asumió. 


\section{ANEXO 1}

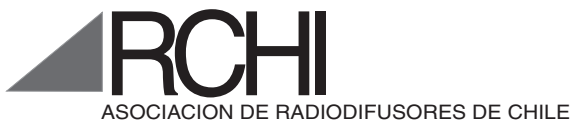

Santiago, Febrero 28 de 1996

Ref.: EC-JH/96 - 017

Senador

Don Miguel Otero Lathrop

Presidente de la Comisión

De Constitución, Legislación

Y Justicia del Senado

Senado de la República.

Honorable señor senador:

La Asociación de Radiodifusores de Chile hace llegar a usted y a la Comisión que tan dignamente preside las opiniones y observaciones que le merecen el proyecto de ley sobre Libertades de Opinión e Información y Ejercicio del Periodismo aprobado por la H. Cámara de Diputados y enviado en oficio 793 de 12 de diciembre de 1995 al señor Presidente del Senado.

Ante todo queremos dejar constancia de nuestra satisfacción por el evidente progreso que el proyecto enviado por el Ejecutivo significa sobre la actual legislación, especialmente cuando una materia tan importante pasa a tratarse desde un plano meramente negativo, como lo era en la Ley de Abusos de Publicidad, a un planteamiento positivo a que lo refiere el proyecto de Ley sobre Libertad de Opinión e Información y Ejercicio del Periodismo.

Se advierte en el texto el interés por modernizar este tipo de normas y aclarar conceptos y procedimientos.

La Asociación de Radiodifusores de Chile, ARCHI, participó tanto en las comisiones preparatorias del proyecto, como en sesiones de trabajo con el Ministerio Secretaría General de Gobierno durante la discusión parlamentaria y con la Comisión de Constitución, Legislación y Justicia de la H. Cámara de Diputados.

En esta última, una serie de indicaciones hicieron peligrar el espíritu mismo de la ley, pero el tema fue zanjado por la sentencia del Tribunal Constitucional.

Respecto al texto que entrará en estudio por la Comisión de su digna presidencia, ARCHI debe hacer algunas observaciones de carácter general y otras específicas. 


\section{OBSERVACIONES DE CARACTER GENERAL}

1.1. Estimamos que en materia de radiodifusión las normas sobre propiedad e inversión extranjera obedecen a distintos padrones de los que rigen en prensa y televisión.

La radio es un medio fundamentalmente estratégico y de gran penetración cultural en la comunidad y además es necesario resguardar su pluralismo y una leal competencia dentro del proceso de globalización e internacionalización de nuestra economía.

De aquí que estimemos fundamental que, manteniendo el principio de una libertad de mercado, se exija total RECIPROCIDAD DE DERECHOS Y OBLIGACIONES respecto a lo existente en el país de origen de las eventuales inversiones extranjeras.

Correspondería al Ministerio de Transportes y Telecomunicaciones, a través de su Subsecretaría de Telecomunicaciones, establecer y autorizar en cada caso estas inversiones teniendo en consideración el respeto de estos principios. Solicitamos que estas normas sean incorporadas en el art. 10 del proyecto en estudio.

1.2. Otra consideración general dice relación con la promoción de los medios regionales de comunicación, indispensable para el desarrollo regional del país.

En esta materia solicitamos que se aseguren recursos regionales existentes para reforzar el financiamiento de estos medios.

El art. 9 del proyecto establece que las autoridades pertinentes deberán disponer fondos del presupuesto del Estado, de sus organismos y empresas, y de las municipalidades, destinados a avisos, llamados a concursos, propuestas y publicidad, que tengan una clara identificación regional, provincial o comunal para destinarlos a efectuar la correspondiente publicación o difusión en medios de comunicación social regionales, provinciales o comunales.

Solicitamos que la expresión "a lo menos en parte" que contempla el artículo, se reemplace por "mayoritariamente" a fin de que se provea realmente a estos medios de mayores recursos para cumplir su misión de ser expresión regional.

\section{COORDINACION CON OTROS CUERPOS LEGALES}

2.1. El art. $1^{\circ}$ del proyecto aprobado por la H. Cámara de Diputados dice en su inciso $4^{\circ}$ que "Toda persona tiene derecho a informarse libremente en las fuentes públicas y en las fuentes privadas que por propia voluntad se hayan hecho accesibles a todos. Este derecho tendrá las solas restricciones que se funden en las normas de reserva legalmente vigentes".

Sobre esta materia hacemos presente a la H. Comisión que en la actualidad existen tres mociones presidenciales relacionadas con esta materia 
y que se hace indispensable tratarlas en conjunto para evitar la aprobación de normas contradictorias o incoherentes.

Las referidas mociones constan del acta de la sesión $\mathrm{N}^{\circ} 38$ de la Honorable Cámara de Diputados de fecha 17 de Enero de 1995 y legislan sobre:

a) Acceso a la información en lo relativo a la probidad del funcionario público y regula el acceso a los documentos que obren en poder de los órganos del Estado, en razón del secreto o reserva que merecen;

b) Conducta contraria a la probidad en que incurre el funcionario que niegue información o documentación que haya sido solicitada en conformidad a la ley; y

c) Acceso a la información administrativa, en virtud del cual se establece que toda persona podrá acceder a los documentos que obren en poder de los órganos de la Administración del Estado y obtener copia de ellos.

Sugerimos a la H. Comisión tener a la vista estas mociones presidenciales al momento de discutir el artículo primero, especialmente el inciso $4^{\circ}$, del proyecto sobre Libertades de Opinión e Información y Ejercicio del Periodismo.

\section{OBSERVACIONES ESPECIFICAS}

3.1. En cuanto al artículo $3^{\circ}$, inciso $2^{\circ}$, no existe en nuestra legislación un sistema de acreditación de los corresponsales extranjeros. Por lo tanto, o se establece éste o se elimina la disposición, ya que de aprobarse en la forma propuesta, no tendría aplicación práctica.

3.2. En cuanto al artículo $8^{\circ}$, en su inciso final se hace referencia a una inhabilidad contemplada en el artículo 44, disposición que no la señala. Sugerimos su eliminación.

3.3. En el art. $9^{\circ}$ se propone que el Estado destine recursos para un fondo destinado a realizar estudios sobre el estado y evolución del pluralismo en el sistema informativo.

Sugerimos:

que sea de público acceso a todas las personas;

financiado exclusivamente por el Estado; y

- que la comisión que lo administre y contrate el estudio esté integrada por las siguientes personas:

- Presidente de la Asociación Nacional de la Prensa, ANP

- Presidente de la Asociación de Radiodifusores de Chile, ARCHI

- Presidente de la Asociación Nacional de Televisión, ANATEL,

- Presidente del Colegio de Periodistas, y

- 3 Directores de Escuelas de Periodismo Universitarias, designados por el Parlamento.

3.4. Entre los artículos eliminados sugerimos la reincorporación de aquella disposición que prohíbe la discriminación entre empresas propie- 
tarias de medios de comunicación social en lo relativo al otorgamiento de concesiones o permisos necesarios para el funcionamiento de estaciones radiodifusoras sonoras o televisivas.

Esta disposición se contemplaba en el artículo 13 del proyecto de ley presentado por el Ejecutivo.

3.5. En cuanto al artículo 14 , inciso $2^{\circ}$, esta norma debe ser compatibilizada con aquellas señaladas en la Ley de Propiedad Intelectual (artículos 30 y 67 de la Ley 17.336)

3.6. En cuanto al penúltimo inciso del artículo 15 , se hace presente la existencia de una Moción de los H. Senadores Horvath, Muñoz Barra, Ríos y Zaldívar don Andrés para modificar la ley 16.643, sobre abusos de publicidad, a fin de establecer el depósito legal sobre publicaciones extranjeras con fines comerciales, agregando dos incisos al artículo $4^{\circ}$.

Esta iniciativa consta del Anexo de documentos al Boletín del $\mathrm{H}$. Senado, sesión $\mathrm{N}^{\circ} 11$ de fecha 4 de Mayo de 1994, siendo conveniente su compatibilización.

3.7. En cuanto a las sanciones contempladas en el artículo 17 inciso final, parece exagerado que el incumplimiento de la obligación establecida en el inciso 22 del artículo $10^{\circ}$ (individualización de los propietarios del medio a disposición del público), sea sancionada además con la suspensión del medio.

3.8. En referencia al artículo 18 del proyecto aprobado por la $\mathrm{H}$. Cámara de Diputados, estimamos inoportuno que el conocimiento de las infracciones contempladas en el Título I, también queden entregadas a los Juzgados del Crimen. Proponemos que tales infracciones sean conocidas por los Juzgados de Policía Local respectivos, dejando para la justicia criminal sólo aquello que diga relación con la comisión de delitos.

3.9. En cuanto a $\operatorname{los}$ incisos $5^{\circ}$ y $6^{\circ}$ del artículo 20 , tal materia debería ser contemplada en una legislación específica referida a la informática. Por otra parte, la aplicación de la norma en lo que se refiere a los medios de comunicación, podría significar consecuencias graves, ya que dado el innegable avance de la computación ha llevado a que en todos ellos existan bases de datos con referencias a personas que pueden ser utilizados con motivo de una crónica o reportaje y la posible comisión de delitos o faltas sólo se concretaría al momento de darse a la publicidad o emitirse y no antes.

3.10. En cuanto al inciso $1^{\circ}$ del artículo 21 , esta obligación es injustificadamente gravosa en lo que respecta a las emisoras de radiodifusión sonora. El hecho de que cualquier persona pueda requerir del medio una copia de lo emitido, aun cuando sea a su propia costa, supone una dotación de infraestructura administrativa y la distracción de personal de gran parte de las emisoras del país no están es disposición de soportar.

Por otra parte estimamos que al efecto, la norma contemplada en el artículo 62 es suficiente, ya que quien quiera examinar el contenido de una emisión recurrirá al Juez correspondiente, como una medida de seriedad adicional. 
3.11. En cuanto al artículo 27, estimamos excesiva la pena allí establecida, sugerimos rebajarla y eliminar la conjunción “y”, reemplazándola por "o".

3.12. En cuanto al artículo 29, estimamos conveniente introducir la expresión "maliciosa" después de atribución, así como la necesidad de precisar los términos de su inciso $2^{\circ}$, dada la amplitud de ellos con su actual redacción.

3.13. Respecto del artículo 30, las expresiones "oportuna”, contenidas en los incisos $1^{\circ}$ y $3^{\circ}$, debieran ser eliminadas, ya que dicha disposición ni ninguna otra señala la oportunidad en que debe efectuarse dicha rectificación.

3.14. El artículo 31, debiera ser coordinado con la resolución definitiva que se adopte respecto de los proyectos de ley indicados en el punto $2^{\circ}$.

3.15. En cuanto al artículo $35^{\circ}$, su normativa deberá ser coordinada con las disposiciones de la Ley $\mathrm{N}^{\circ} 19.423$, publicada en el Diario Oficial del día 20 de Noviembre de 1995, así como con el proyecto de modificación, actualmente en trámite en la Cámara de Diputados.

Por otra parte, en relación con este mismo artículo y con el 34, hacemos presente que en el Boletín de la H. Cámara de Diputados correspondiente a la sesión $\mathrm{N}^{\circ} 3$ de fecha 5 de Octubre de 1995, en la sección documentos, consta el texto del proyecto aprobado por el H. Senado, referente al respecto y protección de la vida privada y a la honra de la persona y su familia, cuyas disposiciones también deberán ser coordinadas con las del presente cuerpo legal.

3.16. En cuanto al artículo 40, nada impide que el Juez renueve la medida cuantas veces lo estime, con lo cual se estaría vulnerando el espíritu de la disposición.

Proponemos se agregue en el inciso $2^{\circ}$, después de "la suspensión", seguido por una coma, lo siguiente; "que podrá ser ejercida por una sola vez en cada instancia".

3.17. En referencia al artículo 42, nos remitimos a lo señalado en el numeral 3.13 precedente.

3.18. En cuanto al registro contemplado en el artículo 43, inciso final, nos parece excesivo que además tales antecedentes deban ser enviados a las Comisiones Preventivas, desde el momento que hay otras autoridades públicas que dispondrán de él.

3.19. En cuanto al artículo $44^{\circ}$, y en general en cuanto al Título V, sugerimos su compatibilización con la Moción de los Diputados Ascencio, Elgueta, León, Cornejo, Reyes, Silva, Seguel, Aguiló, Naranjo y Longthon, iniciativa que tiene por objeto modificar los Códigos de Procedimiento Penal y Código Penal establece derechos a los ofendidos por imputación pública de delitos. (Boletín $\mathrm{N}^{\circ}$ 1546-07) (Boletín de sesiones de la Cámara Sesión $N^{\circ}$ 52, de 23 de Marzo de 1995). 
Agradeciendo al señor Presidente la consideración que tenga hacia estas observaciones y quedando a su entera disposición para concurrir personalmente a alguna sesión de la H. Comisión para aclarar cualquier punto, lo saludan muy atentamente,
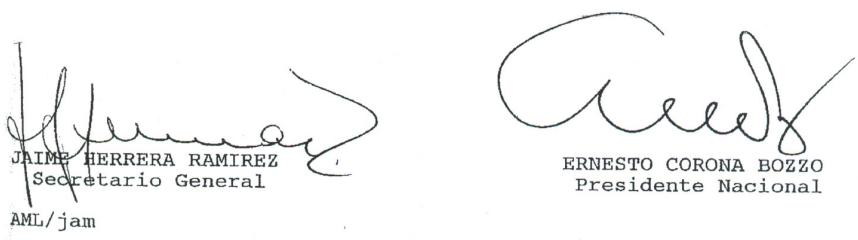

ANEXO 2

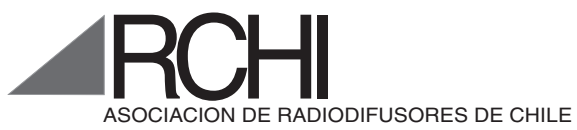

Santiago, 22 de Agosto de 1996

Ref.: CDN/96 - 224

Señor Senador

Don Miguel Otero Lathrop

Presidente de la Comisión de

Constitución, Legislación y Justicia

H. Senado de la República

Valparaíso

Estimado señor senador:

El Consejo Directivo de la Asociación de Radiodifusores de Chile ARCHI, ha acordado en su sesión del día de hoy, dirigirse a usted para solicitarle acoja dos sugerencias de indicaciones al proyecto de ley sobre Libertades de Opinión e Información y Ejercicio del Periodismo, que los radiodifusores de Chile estiman altamente necesarias para el interés nacional y el desenvolvimiento de la radiodifusión. Los textos de estas indi- 
caciones fueron acordados en las dos últimas Juntas Nacionales de nuestra institución, celebradas en 1995 en Iquique y en 1996 en Coyhaique.

La primera dice relación con el proceso de integración de Chile al MERCOSUR y la participación de los radiodifusores en él. Somos fervientes partidarios de la libertad de información y de avanzar en este proceso continental, en condiciones de equidad para las diferentes actividades de los países comprometidos, por lo que estimamos que debe haber similaridad en el tratamiento mutuo para éstas.

La indicación, que podría incluirse como inciso tercero del artículo 92 del proyecto, que trata de los propietarios de los medios, es la siguiente:

"EN EL CASO DE CONCESIONES PARA RADIODIFUSION DE LIBRE RECEPCION SOLICITADAS POR PERSONAS JURIDICAS EXTRANJERAS O CHILENAS, CON PARTICIPACION DE CAPITAL EXTRANJERO, EL MINISTERIO DE TRANSPORTES Y TELECOMUNICACIONES, SOLO PODRA OTORGARLA SI SE ACREDITA, PREVIAMENTE, QUE EN EL PAIS DE ORIGEN SE OTORGAN A LOS CHILENOS DERECHOS Y OBLIGACIONES RECIPROCAS y SIMILARES A LAS CONDICIONES DE QUE GOZARAN ESTOS SOLICITANTES EN CHILE. IGUAL EXIGENCIA DEBERA CUMPLIRSE PARA ADQUIRIR UNA CONCESION EXISTENTE. LA INFRACCION AL CUMPLIMIENTO DE ESTA CONDICION SIGNIFICARA LA CADUCIDAD DE PLENO DERECHO DE LA CONCESION."

La segunda, dice relación con la necesidad de asegurar el pluralismo y la supervivencia de los medios regionales de comunicación social. El principal problema no es la proliferación de nuevos medios, sino de que los actuales tengan financiamiento. Hay que considerar que fuera de la Región Metropolitana hay más de quinientas radios, la mayoría de radiodifusores medianos y pequeños, lo que de por sí, asegura el deseado pluralismo.

Existen interesantes oportunidades de inversión regional en avisajes, fuente del financiamiento de las radios. Con la indicación que se sugiere, se pretende colaborar en la solución de dos problemas: la supervivencia de las radios y la mejor información a las comunidades sobre hechos que les interesan por su ocurrencia local. El texto sugerido es el siguiente, y que podría incluirse como inciso $8^{\circ}$ del proyecto, que se refiere, precisamente, al pluralismo:

"LAS AUTORIDADES PERTINENTES DISPONDRAN QUE, EN PARTE MAYORITARIA, LOS FONDOS QUE ESTABLECEN LOS PRESUPUESTOS Del ESTADO DE SUS ORGANISMOS Y EMPRESAS, Y DE LAS MUNICIPALIDADES, DESTINADOS A AVISOS, LLAMADOS A CONCURSOS, PROPUESTAS Y PUBLICIDAD, QUE TENGAN UNA CLARA IDENTIFICACION REGIONAL, PROVINCIAL O COMUNAL, SEAN DESTINADOS A EFECTUAR LA CORRESPONDIENTE PUBLICACION O DIFUSION EN MEDIOS DE COMUNICACION SOCIAL REGIONALES, PROVINCIALES O COMUNALES.” 
Quedando desde luego muy agradecidos al señor senador por la favorable acogida que nos brinde, y a su disposición para cualquier mayor antecedente, lo saludan atentamente,
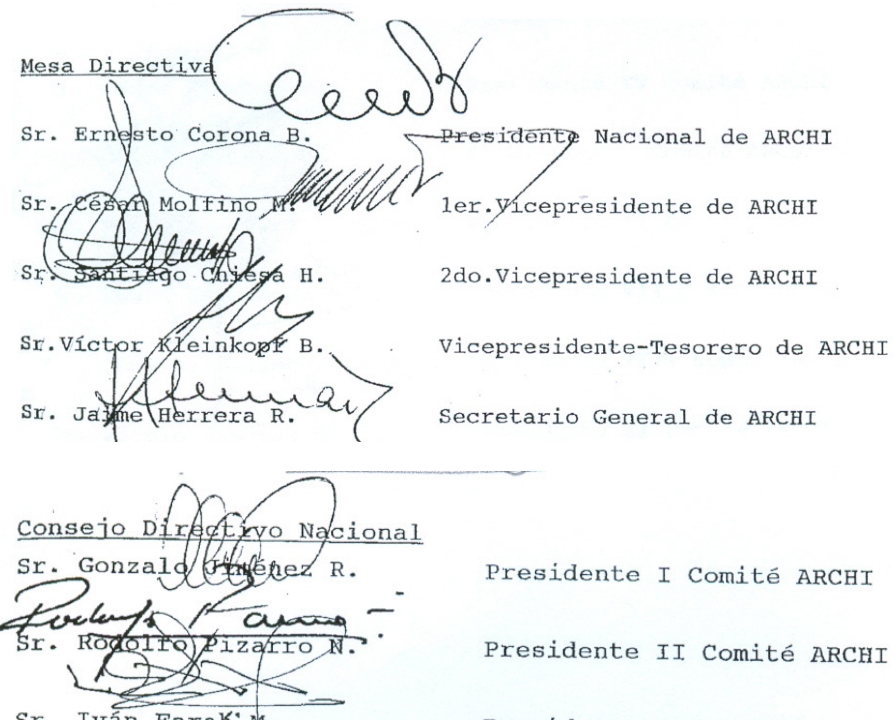

Sr. Ivắn Faraḱ .

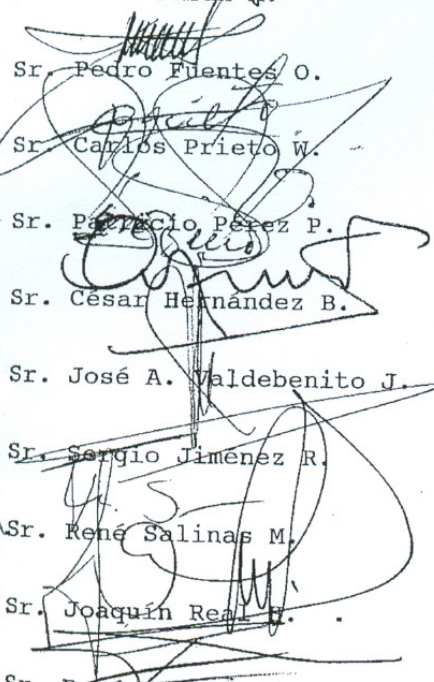

Presidente I Comité ARCHI

Presidente II Comité ARCHI

Presidente III Comité ARCHI

Presidente IV Comité ARCHI

Presidente V Comité ARCHI

Presidente VI Comité ARCHI

Presidente VII Comité ARCHI

Presidente VIII Comité ARCHI

Presidente XI Comité ARCHI

Presidente X Comité ARCHI

Presidente XI Comité ARCHI

Presidente XII Comité ARCHI

Sr. Rickiforifmann L. $\mathrm{AML} / \mathrm{j}$ am

Presidente Comité Metropolit. ARCH 
ANEXO 3

FEDERACIÓN DE MEDIOS

COMUNICACIÓN SOCIAL

Santiago, 5 de Septiembre de 1996

Ref.: ECB/96 - FED/010

Señor Senador

Don Miguel Otero Lathrop

Presidente de la Comisión de

Constitución, Legislación y Justicia

H. Senado de la República

Valparaíso

Estimado señor senador:

Me es grato adjuntarle las observaciones que los Títulos I, II y III del proyecto de Ley de Libertades de Opinión e Información y Ejercicio del Periodismo, merecen a la Federación de Medios de Comunicación Social.

Ellas han sido aprobadas por las Mesas Directivas de la Asociación de Radiodifusores de Chile, ARCHI, de la Asociación Nacional de la Prensa, ANP, y de la Asociación Nacional de Televisión, ANATEL.

Oportunamente, haremos llegar las observaciones referentes a los títulos siguientes del proyecto.

Agradeciéndole desde luego la favorable acogida que la Comisión de su digna presidencia brinde a estas observaciones de la Federación, lo saluda muy atentamente,

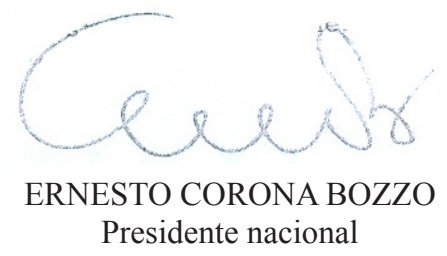

c.c. Sres. senadores Sergio Fernández

Juan Hamilton

Anselmo Sule 


\section{FEDERACIÓN DE MEDIOS DE COMUNICACIÓN SOCIAL}

Fundamento: En el proceso de libertad de comercio e intercambio que Chile está impulsando, con el Mercosur especialmente, es preciso que nuestro país se integre en condiciones de igualdad y equidad con sus vecinos. La radio, por su influencia en la opinión pública y su carácter estratégico en lo geopolítico, requiere de un status de reciprocidad frente a sus socios en la integración. No es justo ni conveniente que, mientras los radiodifusores de otros países pueden establecerse libremente en Chile, los chilenos no puedan instalar emisoras en dichos países. El art. 9 del proyecto de ley, al abolir toda mención a la nacionalidad en la propiedad de los medios, como lo hacía la ley 16.643 sobre Abusos de Publicidad, dejó a la radiotelefonía chilena en inferioridad de condiciones frente a la de otros países. De aquí la necesidad de esta mención especial.

Además, en este mismo art. 9, la Federación propone que en el inciso primero se reemplacen los términos "procesados" y "el auto de procesamiento" por "condenados" y "la sentencia ejecutoriada", respectivamente. Lo mismo debería hacerse en el art. 10.

Fundamento: Esto supone que esté concluido el proceso y existan antecedentes que acrediten la inhabilidad.

Finalmente, en el mismo artículo, se solicita agregar en el inciso $2^{\circ}$, a continuación de la expresión "tratándose de personas jurídicas" la expresión "con excepción de las sociedades anónimas abiertas".

Fundamento: Hacerlo coherente con el inciso $4^{\circ}$ del artículo 11 de la ley.

Art. $13^{\circ}$. Se propone volver a la redacción del art. 14 del texto aprobado por la Cámara de Diputados, pero eliminando la frase final "o difusión televisiva o cinematográfica". El artículo quedaría con el siguiente texto: "Toda persona que tenga a su cargo cualquier tipo de establecimiento impresor deberá poner un pie de imprenta en cada uno de los ejemplares que publique, el cual deberá especificar el nombre del establecimiento, el lugar y la fecha de la impresión.

"Igual obligación tendrán las personas que tengan a su cargo establecimientos de grabación sonora o de producción audiovisual". 


\section{ANEXO 4}

Desde el 4 de junio de 2001, fecha en que entró en vigencia la Ley de Prensa, hasta la discusión que generó la consulta al TDLC por parte de GLR Chile Ltda. en razón de querer comprar a Claxon S.A. todas las acciones de Iberoamerican Radio Chile S.A., el regulador sectorial MTTSUBTEL había otorgado concesiones de radiodifusión sonora y autorizado su adquisición por parte de personas jurídicas vinculadas a las partes de esa operación consultada. En ninguno de estos casos, el regulador sectorial competente hizo cuestión alguna en términos de la regla de reciprocidad.

Así, por ejemplo, y desde el punto de vista de la parte adquirente en la operación, fueron otorgadas dichas concesiones a personas jurídicas vinculadas en última instancia a GLR Chile Ltda. Así, también por ejemplo, las siguientes individualizadas por la fecha del decreto de adjudicación correspondiente, la localidad, la señal distintiva y lugar en el dial FM, y la concesionaria adjudicataria:

- 17/05/2002, Tongoy, señal XQA-410 FM, a Sociedad Publicitaria y Difusora del Norte Ltda.;

- 29/05/2002, Coyhaique, señal XQD-434 FM, a Publicitaria y Difusora del Norte Ltda.;

- 08/07/2002, Viña del Mar, señal XQB-354 FM, a Comunicaciones Santiago S.A.;

- 10/07/2002, Arica, señal XQA-418 FM, Arica, a Comunicaciones Santiago S.A.

Además, la concesionaria Sociedad Publicitaria y Difusora del Norte Ltda. ha adquirido las siguientes concesiones, las cuales fueron aprobadas por el órgano regulador sectorial, sin tampoco hacer cuestión alguna en términos de la regla. Se listan con fecha, localidad, señal distintiva y la persona de quien se adquirió:

- 25/06/2001 (fecha del decreto de aprobación), Coyhaique, señal XQC-339 FM, adquirida de Inversiones Seguel;

- 20/09/2006 (fecha de la escritura de compraventa), Alto Hospicio, señal XQA-381 FM, adquirida de Sociedad de Inversiones Santa Ignacia Ltda.

Respecto de esta última adquisición, el TDLC se pronunció en los términos del artículo 38 de la Ley de Prensa, de una forma que es aquí especialmente significativa. El H. Tribunal tuvo a la vista la malla societaria en que Publicitaria y Difusora del Norte Ltda. se inserta. Y decidió: "Vistos, atendido el nivel de concentración de mercado a nivel regional y nacional que se desprende de la información proporcionada por la consultante y la Fiscalía Nacional Económica, y de los antecedentes públicos recabados por el Tribunal en relación con el grupo controlador al cual pertenece la peticionaria, se informa favorablemente la consulta de fs. 33, por 
estimarse que la transferencia no provocará efectos perjudiciales para la competencia". De nuevo, ni una palabra sobre la regla de reciprocidad.

Es significativo en este caso el hecho de que el H. Tribunal, sin competencia para pronunciarse directamente en términos del artículo noveno de la Ley de Prensa, no haya decidido solicitarle a la SUBTEL investigación alguna con relación a lo dispuesto en ese artículo.

Ahora bien, desde el punto de vista de la parte vendedora en la operación consultada, el regulador sectorial autorizó la adquisición de varios titulares de radiodifusión sonora por parte de Iberoamerican Radio Holdings Uno. Todas estas adquisiciones se hicieron bajo la vigencia de la Ley de Prensa. A continuación se listan, partiendo por la fecha de autorización de la SUBTEL, la localidad, la frecuencia y la persona de quien Iberoamerican Radio Holdings Uno adquirió la concesión:

- 11/01/2002, San Antonio, XQB-299 FM, Comunicaciones de la Costa Ltda.;

- 26/04/2002, Los Angeles, XQC-046 FM, Sociedad Radiodifusora Gutiérrez y González Limitada;

- 26/04/2002, Osorno XQD-381 FM, Comunicaciones de la Costa;

- 27/11/2002, Iquique, XQA-378 FM, Sociedad de Difusión Armonía Limitada;

- 19/12/2002, Osorno XQD-186 FM, Juan Isidro Carrasco Cárdenas;

- 21/04/2003, Talcahuano, XQD-420 FM, Infocom Limitada;

- 17/12/2003, Puerto Montt, XQD-424 FM, Sociedad Redes y Comunicación Limitada.

El TDLC, por su parte, informó favorablemente algunas de estas adquisiciones. Así, por ejemplo, el 12/10/2001².

${ }^{1}$ Rol 78-2005, Solicitud de informe de la Sociedad Publicitaria y Difusora del Norte Ltda., sobre compraventa y transferencia de concesión de radiodifusión sonora propiedad de la Sociedad de Inversiones Santa Ignacia Ltda. (XQA-381 FM, Alto Hospicio), disponible en http://www.tdlc. $\mathrm{cl} /$ informes/detalle.php?id=13.

${ }^{2}$ Rol 178-01, Consulta de la Subsecretaría de Telecomunicaciones, previo a autorizar traspaso de concesión de frecuencia radial FM: Comunicaciones de la Costa Sociedad de Responsabilidad Ltda. a Empresa Iberoamerican Radio Holding Uno Chile (XQD-381 FM). 


\section{BiBLIOGRAFÍA}

Barros, Enrique (1981). "La Interpretación de la Constitución desde la Perspectiva de la Teoría del Derecho". Revista de Derecho Público, Vol. 29-30.

Dromi, José Roberto (1977). La Licitación Pública. Buenos Aires: Astrea.

Centro de Estudios Públicos (1997). Estudio Nacional de Opinión Pública, junio-julio 1997. Documento de Trabajo $N^{\circ} 271$, agosto, disponible en: http://www.cepchile.cl/dms/lang 1/doc 2912.html\#.UKqm0If8LAQ.

Consejo Nacional de Televisión (2005). Encuesta Nacional de Televisión 2005. Principales resultados, disponible en: http://www.cntv. cl/prontus_cntv/site/artic/20110415/asocfile/20110415160901/ principalesresultadosentv2005.pdf.

Jiménez, Juan, Luis Argandoña y Ricardo Torres (2007). “El Fortalecimiento de la Televisión Abierta como Centro de la Dieta Informativa de los Chilenos". En La Función Política de la Televisión. Tendencias, Contenidos y Desafios en el Chile de Hoy. Santiago: Secretaría de Comunicaciones, MINSECGOB, disponible en: http://transparencia. msgg.gov.cl/encuestas/documentos2006/archivo_de_356.pdf.

Marín C., Cristóbal (2007). "Televisión y Transformaciones de la Esfera Pública". En La Función Política de la Televisión. Tendencias, Contenidos y Desafios en el Chile de Hoy. Santiago: Secretaría de Comunicaciones, MINSECGOB, disponible en: http://transparencia. msgg.gov.cl/encuestas/documentos2006/archivo_de_356.pdf

Mir, Oriol (2003). "El Concepto de Derecho Administrativo desde una Perspectiva Lingüística y Constitucional”. Revista de Administración Pública, $\mathrm{N}^{\circ}$ 162, disponible en: http://www.ub.edu/dadmin/OriolMir/ Publicacions/Mir_Concepto_Derecho_administrativo.pdf. 